\title{
Supervisory Incentives in a Banking Union
}




\section{WP/16/186}

\section{IMF Working Paper}

\section{Supervisory Incentives in a Banking Union}

by Elena Carletti, Giovanni Dell'Ariccia, and Robert Marquez

IMF Working Papers describe research in progress by the author(s) and are published to elicit comments and to encourage debate. The views expressed in IMF Working Papers are those of the author(s) and do not necessarily represent the views of the IMF, its Executive Board, or IMF management. 


\title{
IMF Working Paper
}

Research Department

Supervisory Incentives in a Banking Union

Prepared by Elena Carletti, Giovanni Dell'Ariccia, and Robert Marquez

Authorized for distribution by Maurice Obstfeld

September 2016

\begin{abstract}
IMF Working Papers describe research in progress by the author(s) and are published to elicit comments and to encourage debate. The views expressed in IMF Working Papers are those of the author(s) and do not necessarily represent the views of the IMF, its Executive Board, or IMF management.
\end{abstract}

\begin{abstract}
We explore the behavior of supervisors when a centralized agency has full power over all decisions regarding banks, but relies on local supervisors to collect the information necessary to act. This institutional design entails a principal-agent problem between the central and local supervisors if their objective functions differ. Information collection may be inferior to that under fully independent local supervisors or under centralized information collection. And this may increase risk-taking by regulated banks. Yet, a "tougher" central supervisor may increase regulatory standards. Thus, the net effect of centralization on bank risk taking depends on the balance of these two effects.
\end{abstract}

JEL Classification Numbers: G21, G28, D02

Keywords: Centralized bank supervision, bank risk taking, limited liability

Author's E-Mail Address: elena.carletti@unibocconi.it; gdellariccia@imf.org; rsmarquez@ucdavis.edu 


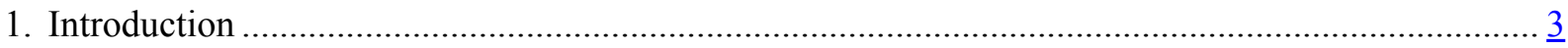

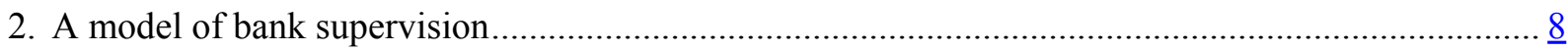

3. The bank's investment choice in the case of no supervision...........................................................10

4. Bank supervision with an independent local supervisor ...............................................................

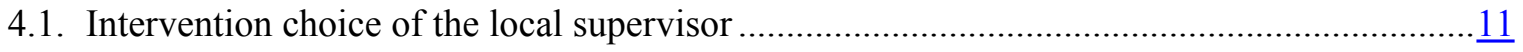

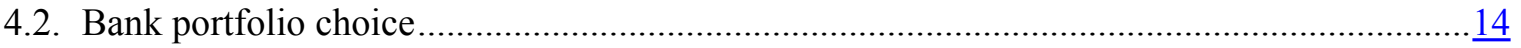

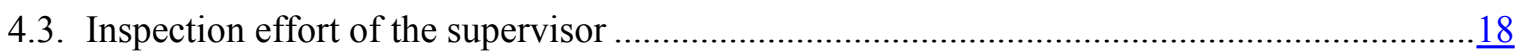

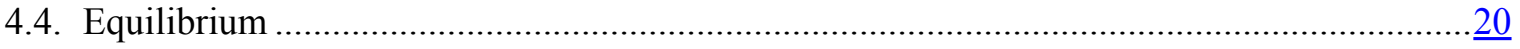

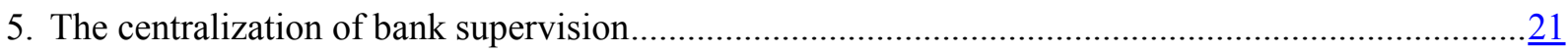

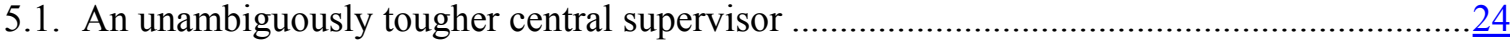

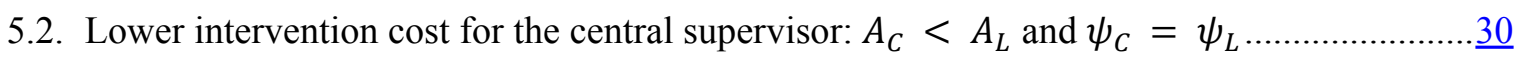

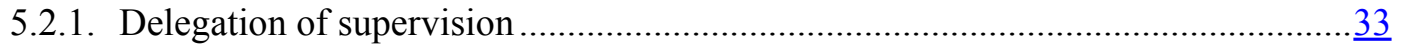

5.2.2. Numerical examples ................................................................................ 34

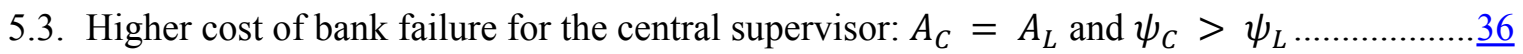

5.3.1. Numerical example....................................................................................

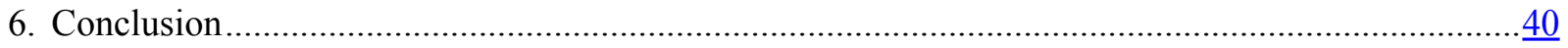

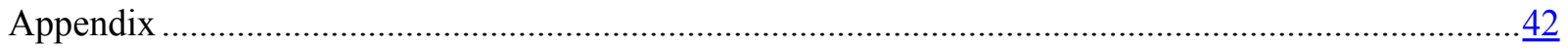

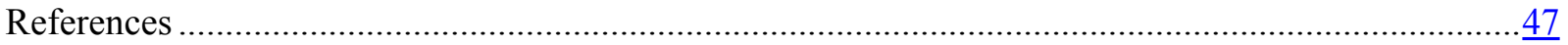

Figures

1. Bank portfolio choice $q$ as a function bank capital $k$, for a given supervisory effort $e$....................16

2. Bank's portfolio choice $q$ as a function of the supervisory effort $e$, for given levels of capital

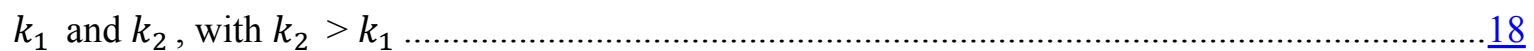

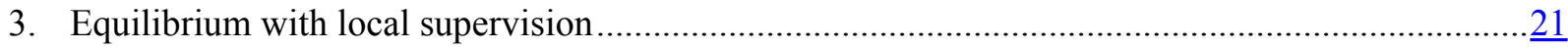

4. Equilibrium with centralized supervision in the case of a tougher central regulator......................... 31

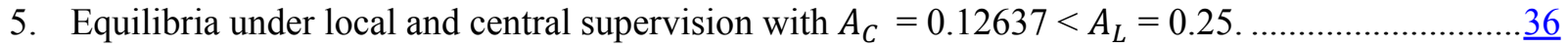

6. Equilibrium with central supervision when supervisors have different shadow costs of funds .........38

7. Equilibrium with local and central supervision with positive regulatory inspection effort for $\psi_{C}=1.45>\psi_{L}=1.15$ 


\section{Introduction}

The global financial crisis laid bare the limitations of a financial architecture in which nationbound supervisors oversaw increasingly integrated financial markets and institutions. Supervisory fragmentation hindered the monitoring and understanding of cross-border linkages before the crisis, and led to often locally-driven and globally-inefficient policy actions after the crisis started. Against this background, the policy debate has focused on the need for greater cross-border integration of financial regulation and supervision, ${ }^{1}$ and the recent regulatory reform in Europe can be seen as an important example in this direction. Yet, the move to greater cross-border coordination and, in some cases, supranational supervision raises new questions about its internal governance, its relationship with local supervisors, and ultimately, the way it will affect the behavior of the financial institutions under its jurisdiction. While the need for and benefits from a more centralized supervisory regime have been discussed at length (Schoenmaker, 2011, Obstfeld, 2014), its costs and challenges have received much less attention.

This paper is a theoretical exploration of the tensions inherent in a "hub-and-spokes" supervisory regime: one in which a centralized agency has legal power over all decisions regarding banks, but has to rely on local supervisors to collect the information necessary to act. In particular, we focus on how this institutional design affects supervisors' incentives to collect information and on how this, in turn, influences bank behavior.

Our stylized framework is broadly applicable to settings where the supervisory structure leads to potential conflict among various agencies, or where there is a hierarchy of supervision and regulation. Hence, the model sheds some light on the challenges facing the centralization of supervision across national borders (as in the recently established Eurozone's banking union) or structures in which multiple agencies have regulatory and supervisory stakes in the same banks (as is the case, for instance, with state-chartered banks in the U.S. - see Agarwal, Lucca, Seru, and Trebbi, 2014). ${ }^{2}$

\footnotetext{
${ }^{1}$ See for instance, IMF (2010) and BIS, (2010).

${ }^{2}$ In its simplicity, our model cannot do justice to the many checks and balances and corrective procedures existing in a real-world supervisory mechanism. Rather, the model is meant to highlight some of the tensions that the new supervisory regime will have to take into account in order to operate effectively. Further, some
} 
We model an economy in which banks, protected by limited liability and operating under asymmetric information, tend to take on excessive risk in the absence of effective supervision. As in many related models, banks are levered and do not take into account the losses they impose on depositors and debt holders (and taxpayers when deposits are insured) when they fail (e.g., Hellmann et al., 2000, Matutes and Vives, 2000, Repullo, 2004, and Dell'Ariccia and Marquez, 2006). Since bank risk taking is not directly observable, investors do not price bank risk correctly at the margin (put differently, market discipline does not guarantee efficiency under asymmetric information). The result is more risk taking than is socially optimal. Bank supervision is designed to improve over this laissez-faire equilibrium.

Under independent supervision, local supervisors invest resources to collect information about banks' portfolios and, upon obtaining it, they can intervene a bank deemed to be too risky (one with too little capital relative to the riskiness of its portfolio) and force it to invest in a safer portfolio deemed optimal by the supervisor. Intervention, however, comes at a cost. This can be seen as a reputational cost for the supervisor, the loss associated with the removal of a national (and private) champion, or it could represent a loss in efficiency associated with the transfer of the bank to the public sector.

Under centralized supervision, local supervisors retain control of information collection, but are mandated to transmit to the central agency what they learn. Then, the central supervisor can act on the information and has full control over the decision of whether or not to intervene a bank, and what portfolio to implement conditional on intervention. Critically, local supervisors have objectives that are different, perhaps just slightly, from those of the central agency, and are in general less inclined to intervene in banks. Such reluctance to intervene may stem from greater costs that are borne at the local level for the supervisor, such as the aforementioned reputational costs and/or fiscal costs, or may reflect some degree of regulatory capture to which a central supervisor would not be subject (see Agarwal, Lucca, Seru, and Trebbi, 2014, and Acharya, Dreschler, and Schnabl, 2013 for supporting evidence). This generates a principal-agent problem between the central and local supervisors, in addition to that between supervisors and banks, that is at the core of of the existing regional supervisory regimes have embraced models in which local supervisory agencies no longer exist. Obviously, our model is less relevant for those cases. 
our model. Information collection will be distorted away from what would happen in a model with fully independent local supervisors or one where the central agency is able to directly collect information. The reason is that local agents will, in some states of the world, prefer to remain ignorant rather than to learn information that would lead the central supervisor to decisions that are against the local supervisor's own interests.

This poorer information collection entails costs. The problem for the central agency is obvious. But the lack of information can also lead to results that are undesirable for local supervisors, and may lead to inefficient outcomes in terms of bank intervention. This, in turn, may lead to poorer ex ante incentives for regulated banks: a lower probability of having their actions discovered will make it more attractive for banks to take risk in excess of what is desired by the regulator. That said, to the extent that a central supervisor imposes tighter standards (tolerates less risk taking) than local ones, for some banks this effect will be partly offset by a lower threshold for intervention. The net effect of supervision centralization is thus ambiguous. When the principal-agent problem between the central and local supervisors is not too severe, supervision centralization will lead to better outcomes in terms of stricter supervision and a safer banking sector. By contrast, when the principal-agent problem is severe enough to lead to lower information collection on the side of the local supervisor, supervision centralization may lead to increased overall risk of the banking sector despite the higher supervisory standards.

The paper makes two main contributions. First, it develops a model of bank supervision where the supervisor's behavior and banks' risk taking incentives are endogenous. This allows us to shed light on how the governance structure within a supervisory framework interacts with bank behavior in determining equilibrium outcomes in terms of risk taking and expected output. To the best of our knowledge, there is little work formally studying bank supervision in this type of setting. Moreover, what emerges in our model are risk-based capital standards: supervisors are willing to tolerate greater levels of risk in the portfolios of better capitalized banks. Banks, in turn, have greater incentives to choose safer portfolios the more capital they have at risk. Second, the paper introduces centralized supervision and analyzes how the agency problems between the local and the central supervisors interact 
with banks' risk taking incentives.

The paper is relevant for the nascent banking union in Europe, as well as for the bank supervisory structure in the US, with multiple independent agencies. As of November 2014, the Single Supervisory Mechanism (SSM), which resides within the European Central Bank (ECB), became the primary supervisor of the Eurozone's biggest banks. It supervises directly the largest 128 banks in the Eurozone, accounting for approximately 85 percent of banking assets of the area, and indirectly all the banks in the Eurozone. Yet, at least for a prolonged transition period, one can realistically assume that the ECB will have to rely heavily on local supervisors for the collection and processing of on-site information. Then, our paper suggests that internal mechanisms need to be devised to guarantee that the spokes, which may have different objective functions from the hub, act according to the centralized mandate. Various elements of the new institutional design go in this direction. For instance, the ECB retains the right to bring any bank (in addition to the top 128) under its direct supervision. In our model, this kind of threat would act as a disciplining device for local regulators. Also, multi-country teams headed by ECB officials may conduct on-site inspections at the largest banks; again a move that facilitates the exchange of information between the spokes and the hub.

This paper contributes to the literature on the benefits and challenges of centralized bank regulation and supervision. In this respect the paper is related to Acharya (2003), Dell'Ariccia and Marquez (2006), Morrison and White (2009), Calzolari and Loranth (2011), Calzolari, Colliard, and Loranth (2015), Goyal et al. (2013), Beck and Wagner (2014), Beck, Todorov, and Wagner (2013), and the discussions in Basel Committee on Banking Supervision (2010) and IMF (2010). All of these papers discuss aspects of the regulation of multinational banks, and the issues that may arise when (local) regulators do not fully take into account effects stemming from a bank's international activities on foreign investors/depositors. There is also a recent related literature on the regulation of banks within a banking union which focuses on how the supervisory architecture may be an important determinant of the effectiveness of regulation (e.g., Colliard, 2015). Our paper instead studies how centralization of supervision, while serving to "toughen" supervisory standards, may create an agency 
problem vis a vis the institutions mandated with implementing the centralized policies. In this respect, it is closer to Holthausen and Rønde (2004), who focus on the difficulties in getting local agencies to credibly transmit information to central agencies.

Recent research also explores the question of bank resolution in the context of multinational global banks. For instance, Bolton and Oehmke (2015) consider how a single point of entry resolution, where loss absorbing capacity is shared across jurisdictions, may be efficient but not always feasible, requiring supervisors to pursue a multiple points of entry approach, where individual jurisdictions must bear well-defined portions of the losses. ${ }^{3}$ While not addressing the issue of bank closure directly, our paper focuses on intervention policies geared toward keeping the bank running, but with a portfolio that is more closely aligned with the objectives of the supervisor.

Our paper is also related to the literature on the delegation of authority within firms or organizations. For instance, Aghion and Tirole (1997) focuses on how granting "real" authority to agents - the effective control over decisions - can often improve decision making and lead to better investment outcomes, even when the principal has "formal" authority, defined as the explicit right to make decisions. In that setting, real authority can be seen as a form of delegation by the principal to an agent, which improves incentives for the agent, and which can ultimately benefit the principal as long as the agent's objectives are not too dissimilar to those of the principal. Our finding that effort by the local supervisor may either increase or decrease under centralization when the central and local supervisors have different intervention costs, or view the costs of bank failure differently, is thus reminiscent of that literature. At the extreme, the central supervisor may find it optimal to not take control over supervisory decisions, thus fully delegating all supervisory actions to the local supervisor.

The paper proceeds has follows. Section 2 describes the basic model with a local independent supervisor. Section 3 derives the bank's portfolio choice in the case of no supervision. Section 4 derives the equilibrium in the case of an independent local supervisor, while Section

\footnotetext{
${ }^{3}$ Other contributions focus on bank closure and resolution policy in single jurisdictions, abstracting from possible global activities of banks. These include Mailath and Mester (1994) and, more recently, Morrison and White (2013) and Walther and White (2015).
} 
5 discusses the effects of centralizing supervision. Section 6 concludes.

\section{A model of bank supervision}

Consider a simple one-period economy with banks, investors and a local supervisor. Each bank has access to a risky investment portfolio and needs external funds to finance it. The supervisor may observe each bank's portfolio and decide to intervene the bank or let it operate. Finally, the bank's portfolio returns are realized and the bank either succeeds or fails.

Specifically, banks' investment portfolio requires 1 unit (or dollar) of funds. Each bank is endowed with an amount of capital $k \in[0,1]$ and raises an amount of deposits $1-k$ from outside investors. Bank capital is distributed according to the cumulative distribution $F(k)$, with density $f(k)$. For tractibility, we will assume $k$ to be distributed according to a uniform distribution in the interval $[0,1]$. The distribution $F($.$) of bank capital is common$ knowledge and thus can be viewed as the supervisor's priors concerning any given bank.

Depositors receive a promised (per dollar) return $r_{D}$ and have a total per dollar (normalized) opportunity cost of 1 . The deposit market is perfectly competitive so that the bank will always set $r_{D}$ at the level required for depositors to recover their opportunity cost of funds and be willing to participate. For simplicity, we consider that deposits are fully insured so that $r_{D}=1$ and that there is no differential cost between equity and debt financing so that we normalize also the per dollar opportunity cost of capital to 1 .

The bank chooses a portfolio on the efficient frontier, where that frontier is defined as follows: if a portfolio with probability of repayment $q$ is chosen, the return on the portfolio is $R-\frac{1}{2} c q$. In other words, the bank can choose the level of risk it likes, with the implication that a higher risk (i.e., lower $q$ ) portfolio has a higher return if successful. This gives a familiar risk-return tradeoff.

The local supervisor may decide to inspect the bank and observe the quality of the bank's portfolio. Specifically, the supervisor chooses initially an inspection effort $e$ at a cost $\frac{d}{2} e^{2}$, which represents the probability of observing the portfolio $q$ chosen by the bank, as well as the 
bank's level of capital (i.e., the supervisor observes the bank's balance sheet). ${ }^{4}$ Conditional on the result of the inspection, the supervisor decides whether to intervene the bank or let it operate independently. If intervened, the bank is put under receivership with probability $\eta$. In this case, existing shareholders are expropriated and, at a cost $A_{L}$, the supervisor takes control over the bank's investment choice and chooses the investment portfolio that maximizes total social surplus. ${ }^{5}$ The parameter $\eta$ represents then a measure of the bank's ability to challenge the intervention decision of the supervisor, possibly through lobbying activities or through the courts. The cost $A_{L}$ can be seen as capturing the reputation cost the regulator bears when intervening a bank under her control, the cost associated with the loss of a national champion or the loss in efficiency associated with the transfer of the bank to the public sector (this might also include the cost of reallocating the bank portfolio).

Irrespective of whether she has intervened the bank, the supervisor provides deposit insurance. In other words, the supervisor repays depositors when, with probability $1-q$, the bank's investment returns 0 at the end of the game. Bank failure is socially costly, and is reflected in a (per dollar) cost $\psi_{L} \geq 1$ borne by the supervisor when the bank fails and depositors need to be repaid. The cost $\psi_{L}$ represents the cost of externalities associated with bank failure, which grows with the size of the realized losses to bank depositors.

The timing of the model is as follow. In stage 0 , a bank with capital $k$ chooses its investment portfolio and the local supervisor chooses the inspection effort $e$. In stage 1, with probability $e$, the supervisor observes $q$ and $k$, and decides whether to intervene. If intervened, with probability $\eta$ the bank is put under receivership and the supervisor's preferred investment portfolio is chosen. If not intervened, with probability $(1-e \eta)$, the bank continues with its prior choice of portfolio quality $q$. In either case, in stage 2 , the investment portfolio

\footnotetext{
${ }^{4}$ We assume that the supervisor has a prior about any given bank's level of capital $k$, which is given by the distribution $F($.$) , but that observing the bank's exact level of capitalization requires inspection. This$ is consistent with the view that regulatory capital (the relevant variable in the model, since the outcome of supervision will be the development of risk-weighted capital standards, as we show below) comprises various instruments whose values and usage may not be easily determined without closer inspection. This is the case, for instance, for Tier II capital, an important component of regulatory capital, but which incorporates items such as loan-loss reserves, subordinated debt, etc.

${ }^{5}$ By assuming that shareholders of an intervened bank are fully expropriated, we are in essence allowing the supervisor to employ maximal punishments. These punishments then have the largest incentive effects for banks. In practice, intervention tends to take a more gradual approach.
} 
returns are realized, and depositors obtain their promised return $r_{D}$ either from the bank or the supervisor. Capital providers obtain the remaining profits from the bank's portfolio after repaying depositors when the bank is not intervened and the portfolio succeeds. Otherwise, they obtain zero. In order for them to be willing to participate, shareholders must obtain at least $r_{E}$ in expectation.

\section{The bank's investment choice in the case of no su- pervision}

We start by considering the bank's individually optimal investment under laissez-faire, that is in the absence of regulation. The bank chooses the quality of the investment portfolio $q$ so as to maximize expected profits. The bank has some capital $k$ and must finance the rest with deposits. The bank's objective function reflects the fact that it is protected by limited liability:

$$
\max _{q} q\left(R-\frac{1}{2} c q-(1-k)\right)-k,
$$

that is the bank pays back its depositors, $1-k$, only when its investment is successful, which occurs with probability $q$. Thus, in the absence of regulation, the bank chooses an investment portfolio of quality $\widehat{q}(k)$, where

$$
\widehat{q}(k)=\frac{R-(1-k)}{c} .
$$

The bank's optimal portfolio choice is increasing in $k$ because of limited liability: the bank does not internalize the losses that accrue to depositors (or taxpayers given the assumption of deposit insurance) in case of failure. This "skin-in-the-game" effect implies that high capital banks will choose low risk portfolios, and low capital banks will choose high risk portfolios. A bank that was fully equity financed would choose $\widehat{q}(1)=\frac{R}{c}$.

This framework implies a moral hazard problem in the choice of the investment portfolio quality when the bank raises a positive amount of deposits, and it is the justification for regulation in this framework. The quality of the investment portfolio may be so low that it may be welfare enhancing for the supervisor to intervene and take over control of the bank's 
investment. This is precisely what we analyze next, starting with the case when there is only a local supervisor that chooses both the inspection effort and the intervention strategy.

\section{Bank supervision with an independent local super- visor}

In this section, we consider the case where there is only a local supervisor that chooses an inspection effort $e$ and an intervention strategy, which amounts to an intervention threshold and a portfolio choice for the bank upon intervention. The model is solved backward. We first analyze the supervisor's intervention decision conditional on her inspection having been successful, and then look at the choice of effort $e$.

\subsection{Intervention choice of the local supervisor}

Upon learning the bank's portfolio - asset allocation and liabilities - the supervisor chooses whether to intervene so as to maximize total surplus, which includes financial as well as possible non-pecuniary returns. Given a portfolio choice $q$ by a bank with capital $k$, if the supervisor decides not to intervene, her payoff is given by:

$$
q\left(R-\frac{1}{2} c q-(1-k)\right)-(1-q)(1-k) \psi_{L}-k .
$$

The first term is the bank's expected profit, gross of the opportunity cost of capital $k$. The second term is the payoff when, with probability $1-q$, the bank's portfolio fails and returns 0 . In this case, the $1-k$ of deposits are repaid through deposit insurance at the per dollar $\operatorname{cost} \psi_{L}$. The last term is the opportunity cost of capital $k$ that is employed in the investment portfolio.

In case the supervisor decides to intervene, his payoff is instead given by

$$
\begin{aligned}
& \eta\left(-A_{L}+q_{L}^{*}\left(R-\frac{1}{2} c q_{L}^{*}-(1-k)\right)-\left(1-q_{L}^{*}\right)(1-k) \psi_{L}\right) \\
& +(1-\eta)\left(q\left(R-\frac{1}{2} c q-(1-k)\right)-(1-q)(1-k) \psi_{L}\right)-k
\end{aligned}
$$

where

$$
q_{L}^{*}(k)=\frac{R+(1-k)\left(\psi_{L}-1\right)}{c}
$$


is the portfolio quality chosen by the supervisor to maximize her payoff in the case of intervention as given in (3). Note that, for $k<1$, we have $q_{L}^{*}>\widehat{q}(1)=\frac{R}{c}$ as the supervisor takes into account the cost of failure, $\psi_{L}>1$, while a fully equity financed bank does not entail any spillover cost of failure. It is important to also note that this optimal portfolio quality $q_{L}^{*}$ should be viewed as a choice of bank portfolio risk relative to bank capitalization, with the supervisor preferring that less capitalized banks take less risk: $\frac{\partial q_{L}^{*}}{\partial k}<0$. At the limit, if $k=1$ so that the bank is all equity financed, $q_{L}^{*}=\widehat{q}$, and there is no need for intervention.

The first term in (3) represents the payoff to the supervisor when intervention is successful. In this case, which occurs with probability $\eta$, the supervisor pays the cost of intervention $A_{L}$ and obtains a net expected surplus from investing in a portfolio of quality $q_{L}^{*}$. With probability $q_{L}^{*}$ the investment yields a return net of depositors' repayment of $R-\frac{1}{2} c q_{L}^{*}-(1-k)$, and with probability $1-q_{L}^{*}$ it fails and the $1-k$ deposits are repaid through deposit insurance, entailing a per dollar cost $\psi_{L}$. The second term in (3) represents instead the payoff to the supervisor when, with probability $1-\eta$, the intervention is not successful and the bank continues to operate with its original portfolio. The last term is again the opportunity cost of the capital $k$ employed in the bank's investment.

Let $I_{L}\left(q_{L}^{*}, q, k\right)$ indicate the difference between the intervention and no intervention payoffs for the supervisor as given in equations (3) and (2) when she implements $q_{L}^{*}$ under intervention, the bank chooses $q$ under no intervention and has a level of capital $k$. Substituting the relevant expressions we then have

$$
\begin{aligned}
I_{L}\left(q_{L}^{*}, q, k\right) & =\eta\left(-A_{L}+q_{L}^{*}\left(R-\frac{1}{2} c q_{L}^{*}-(1-k)\right)-\left(1-q_{L}^{*}\right)(1-k) \psi_{L}\right) \\
& -\eta\left(q\left(R-\frac{1}{2} c q-(1-k)\right)-(1-q)(1-k) \psi_{L}\right) .
\end{aligned}
$$

In what follows, we assume $-A_{L}+q_{L}^{*}\left(R-\frac{1}{2} c q_{L}^{*}-1\right)-\left(1-q_{L}^{*}\right) \psi_{L}>0$ so that, at least for banks with zero capital, intervention does not entail any social loss. Moreover, we also assume that intervention is always desirable for banks with no capital. Formally, this means $I_{L}\left(q_{L}^{*}, q, k\right)>0$ for $k=0$. After substituting the expression for $q_{L}^{*}$ into (5), this boils down to requiring that $\psi_{L}>\sqrt{2 c A_{L}}$. That is, the cost of intervention is "small enough" relative to the social cost of bank failure. We have then the following immediate result. 
Proposition 1 When acting independently, the local supervisor chooses to intervene a bank with capital $k$ if $q<\widetilde{q}_{L}(k)$, where

$$
\widetilde{q}_{L}(k)=\frac{1}{c}\left(R+(1-k)\left(\psi_{L}-1\right)-\sqrt{2 c A_{L}}\right) .
$$

It follows that $\frac{\partial \widetilde{q}_{L}(k)}{\partial k}<0, \frac{\partial \widetilde{q}_{L}(k)}{\partial \psi_{L}}>0$ and $\frac{\partial \widetilde{q}_{L}(k)}{\partial A_{L}}<0$.

The proposition states that the local supervisor will intervene when the quality of the bank's portfolio is too low relative to its capitalization. Again, as for the optimal portfolio $q_{L}^{*}$ conditional on intervention, the threshold for intervention $\widetilde{q}_{L}(k)$ is a function of a bank's actual level of capital. Specifically, $\widetilde{q}_{L}(k)$ defines a schedule of thresholds as a function of $k$, with $\widetilde{q}_{L}$ decreasing in $k$. This implies that the supervisor is willing to be more lenient with better capitalized banks in the sense of allowing a bank with more capital to operate with a riskier portfolio. The reason is that the social cost of failure, $(1-k)\left(\psi_{L}-1\right)$, is lower the more capital the bank has. This leads the supervisor to be less inclined to intervene more capitalized banks. ${ }^{6}$ In other words, the optimal intervention policy takes the form of a risk-based capital requirement: banks with riskier portfolios are required to hold more capital. $^{7}$

It follows from the arguments above that, for a given level of capital $k$, the threshold $\widetilde{q}_{L}(k)$ increases with the per dollar cost $\psi_{L}$ of bank failure, so that an increase in $\psi_{L}$ makes the supervisor more prudent. This means that the prospect of more costly externalities associated with failure leads to a more aggressive "prompt corrective action" stance.

Finally, for any given level of capital $k$, the critical portfolio quality $\widetilde{q}_{L}$ below which a bank is intervened is lower than the supervisor's choice of investment quality $q_{L}^{*}$ because of the intervention cost $A_{L}$. This implies that banks with investment portfolios of quality $q \in\left(\widetilde{q}_{L}, q_{L}^{*}\right]$ are not intervened. In the absence of the intervention cost (i.e., if $\left.A_{L}=0\right)$,

\footnotetext{
${ }^{6}$ As we show below, however, this will nevertheless translate into a unique capital threshold below which intervention occurs, and above which the bank is allowed to continue. The decreasing nature of $\widetilde{q}_{L}$ with respect to $k$ does, however, influence bank behavior, as we discuss further below.

${ }^{7}$ Since our choice variable throughout is portfolio quality $q$, we present our analysis in the context of interventions that shift banks' portfolios toward less risk (higher $q$ ). However, since both the intervention threshold $\widetilde{q}_{L}(k)$ and the supervisor's preferred portfolio $q_{L}^{*}(k)$ are functions of the bank's capital $k$ (i.e., they are risk-based capital requirements), we could alternatively view the supervisor as requiring intervened banks to recapitalize to achieve the optimal risk to capital ratio implied by $q_{L}^{*}(k)$.
} 
$\widetilde{q}_{L}=q_{L}^{*}$. It follows that the supervisor becomes laxer in her intervention decisions as the cost $A_{L}$ increases.

\subsection{Bank portfolio choice}

Now consider how the bank's portfolio choice changes once we introduce the possibility of regulatory action. For a choice of portfolio quality $q$, the bank's profit function can be rewritten as

$$
\Pi=\left\{\begin{array}{l}
q\left(R-\frac{1}{2} c q-(1-k)\right)-k \text { for } q \geq \widetilde{q}_{L} \\
(1-e \eta) q\left(R-\frac{1}{2} c q-(1-k)\right)-k \text { for } q<\widetilde{q}_{L} .
\end{array}\right.
$$

The first expression in (7) represents the expected profit for a bank with portfolio quality $q \geq \widetilde{q}_{L}$. The second line is instead the expected profit for a bank with $q<\widetilde{q}_{L}$, which obtains a positive payoff only when, with probability $1-e \eta$, it is not intervened and can continue the investment and obtains in expectation $q\left(R-\frac{1}{2} c q-(1-k)\right)$.

It is immediate to see that the threat of regulatory intervention may affect a bank's portfolio choice. In particular, banks with a level of capital $k$ such that their laissez-faire optimal portfolio $\widehat{q}(k)$, as defined in $(1)$, is greater than the intervention threshold $\widetilde{q}_{L}(k)$, as defined in Proposition 1, will not be affected by the threat of regulatory intervention and will continue to choose their desired portfolio $\widehat{q}(k)$. By contrast, banks whose capital $k$ is such that $\widehat{q}(k)<\widetilde{q}_{L}(k)$ have to take into account that, with probability $e \eta$, they will be intervened and lose their franchises. This implies that some of these banks, and in particular those with a level of capital such that the difference $\widetilde{q}_{L}(k)-\widehat{q}(k)$ is small enough, may opt for the portfolio $\widetilde{q}_{L}$ in order to avoid the risk of intervention.

To see this formally, we proceed in steps. Recall that the regulatory threshold $\widetilde{q}_{L}(k)$ for intervention decreases with $k$, while the laissez faire choice $\widehat{q}$ increases with $k$. This implies that the difference $\widetilde{q}_{L}(k)-\widehat{q}(k)$ is decreasing in $k$ and there is a unique level of bank capital $k$, denoted $\widetilde{k}_{L}$, at which $\widetilde{q}_{L}(k)=\widehat{q}(k)$. Equating (1) and (6) and solving for $k$ gives

$$
\widetilde{k}_{L}=\left(1-\frac{1}{\psi_{L}} \sqrt{2 c A_{L}}\right) \text {. }
$$

Under the assumption that $\psi_{L}>\sqrt{2 c A_{L}}$, which, as argued above, guarantees that interven-

tion is at least sometimes optimal, we have $\widetilde{k}_{L} \in(0,1)$. It follows that banks with $k \geq \widetilde{k}_{L}$ will 
continue finding it optimal to choose their laissez-faire portfolio $\widehat{q}(k)$ and won't be intervened since this portfolio is already safer than the intervention threshold $\widetilde{q}_{L}(k)$. These banks are thus unaffected by the presence of a supervisor. By contrast, banks with capital $k<\widetilde{k}_{L}$, and thus $\widehat{q}(k)<\widetilde{q}_{L}(k)$, will compare their expected profit when choosing $\widehat{q}(k)$ with that when switching to $\widetilde{q}_{L}(k)$. Using $(7)$, the expected profit is given by

$$
\left.\Pi(\widehat{q})\right|_{k<\widetilde{k}_{L}}=(1-e \eta) \widehat{q}\left(R-\frac{1}{2} c \widehat{q}-(1-k)\right)-k
$$

in the former case and by

$$
\left.\Pi\left(\widetilde{q}_{L}\right)\right|_{k<\widetilde{k}_{L}}=\widetilde{q}_{L}\left(R-\frac{1}{2} c \widetilde{q}_{L}-(1-k)\right)-k
$$

in the latter. Clearly, a bank with capital $k<\widetilde{k}_{L}$ will choose to switch to the supervisory intervention threshold $\widetilde{q}_{L}(k)$ if $\left.\Pi\left(\widetilde{q}_{L}\right)\right|_{k<\widetilde{k}_{L}}>\left.\Pi(\widehat{q})\right|_{k<\widetilde{k}_{L}}$, and will stick to the laissez-faire portfolio $\widehat{q}(k)$ otherwise. We have the following result.

Lemma 1 For a given level of supervisory effort e, there exists a level of capital $\bar{k}_{L}(e)$ such that banks with $k<\bar{k}_{L}(e)$ choose the laissez-faire portfolio quality $\widehat{q}(k)$, while banks with $k \geq \bar{k}(e)$ switch to a portfolio of quality $\widetilde{q}_{L}(k)$, where

$$
\bar{k}_{L}(e)=\left(1-\frac{R \sqrt{e \eta}+\sqrt{2 c A_{L}}}{\psi_{L}+\sqrt{e \eta}}\right)<\widetilde{k}_{L} .
$$

It follows that $\frac{\partial \bar{k}_{L}(e)}{\partial e}<0, \frac{\partial \bar{k}_{L}(e)}{\partial \psi_{L}}>0$ and $\frac{\partial \bar{k}_{L}(e)}{\partial A_{L}}<0$.

The lemma shows that, for a given regulatory effort, the threat of intervention affects the portfolio choice of banks with capital in an intermediate range, $k \in\left[\bar{k}_{L}(e), \widetilde{k}_{L}\right)$, as it induces them to switch from their laissez-faire portfolio quality $\widehat{q}(k)$ to the less risky portfolio $\widetilde{q}_{L}(k)$ and meet the supervisor's standards.

The threshold level $\bar{k}_{L}(e)$ is decreasing in the supervisory effort $e$, meaning that banks with increasingly lower levels of capital will choose to meet the supervisory standards as $e$ increases. Moreover, $\bar{k}_{L}(e)$ increases with the cost of bank failure $\psi_{L}$, while it decreases with the cost of regulatory intervention $A_{L}$. This means that a decrease in $\psi_{L}$ or an increase in $A_{L}$ induces banks with even lower levels of capital to meet the supervisory standards. The 


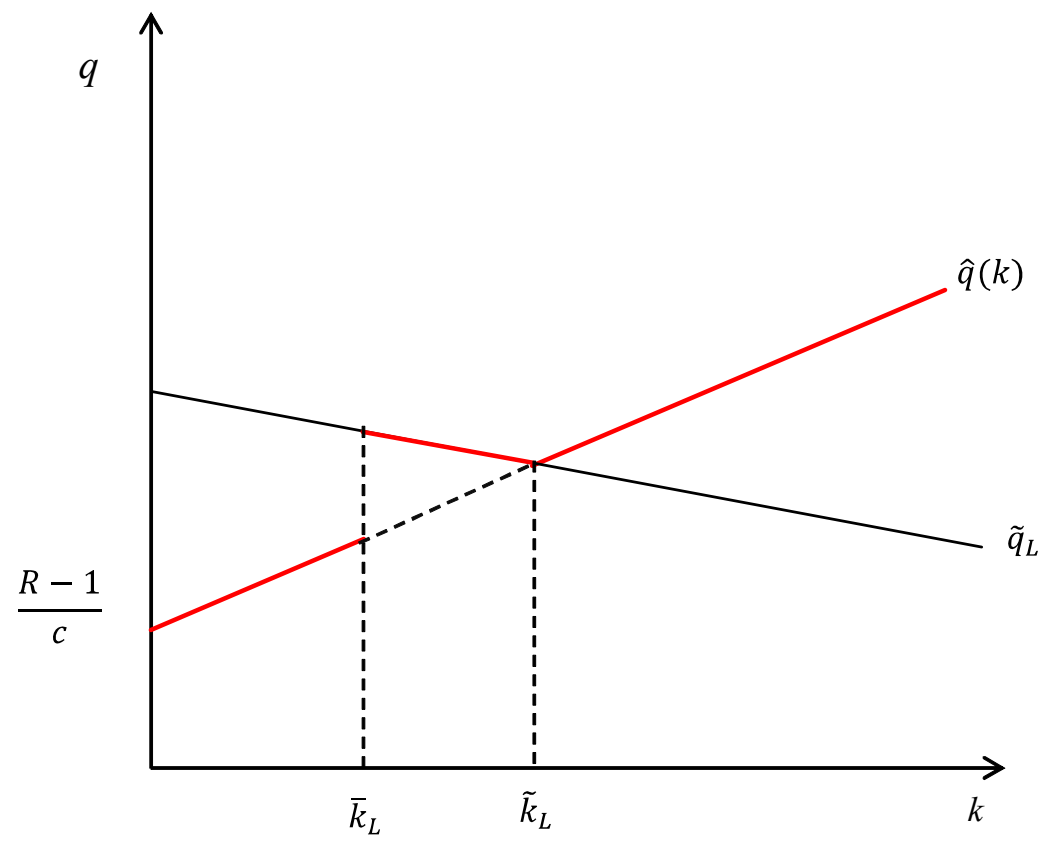

Figure 1: Bank portfolio choice $q$ as a function bank capital $k$, for a given supervisory effort $e$.

reason for these results is that, for a given level of supervisory effort $e$, these parameters affect the intervention threshold $\widetilde{q}_{L}(k)$, as stated in Proposition 1 . When $\widetilde{q}_{L}(k)$ decreases, as for example as a result of a decrease in $\psi_{L}$ or an increase in $A_{L}$, the supervisor is more lenient in that she allows banks with lower portfolio quality to continue. This will induce banks with lower capital to choose $\widetilde{q}_{L}(k)$ as the difference between $\widetilde{q}_{L}$ and their laissez-faire optimal $\widehat{q}(k)$ is reduced.

Figure 1 describes graphically the relationship between the bank portfolio choice as a function of $k$ for a given supervisory effort $e$. As the figure illustrates, banks choose their laissez-faire portfolio quality $\widehat{q}$ for $k<\bar{k}(e)$ and for $k>\widetilde{k}_{L}$. In the former case, $\widehat{q}$ is less than $\widetilde{q}_{L}$ and banks risk to be intervened with probability $e \eta$, while in the latter case $\widehat{q}>\widetilde{q}_{L}$ and thus these banks will always be allowed to continue operating. Banks with $k \in\left[\bar{k}_{L}(e), \widetilde{k}_{L}\right)$ deviate from their laissez-faire portfolio and choose $\widetilde{q}_{L}$ to meet the supervisor's risk-based capital requirement and thus avoid being intervened.

To guarantee that supervisory intervention is meaningful in the model, in what follows we 
will restrict parameters so that the threshold $\bar{k}_{L}(e)$ is positive. This requires the parameters $R, \psi_{L}, A_{L}$ and $c$ to be such that in equilibrium the supervisor will choose an inspection effort $e<\bar{e}_{L}$ where, by setting (11) equal to zero, we have

$$
\bar{e}_{L}=\frac{\left(\psi_{L}-\sqrt{2 c A_{L}}\right)^{2}}{\eta(R-1)^{2}} .
$$

Lemma 1 above characterizes a bank's behavior for a given anticipated supervisory effort $e$ and level of capital $k$. Note, however, that since the threshold value $\bar{k}_{L}$ is a function of effort $e$, the point at which a bank switches from its laissez faire choice $\widehat{q}$ to the supervisory threshold $\widetilde{q}_{L}$ is also a function of $e$. An alternative way of viewing the relationship between bank portfolio choice and supervisory effort is to consider the bank's portfolio choice directly as a function of $e$ given a particular level of $k$. Specifically, for $k<\widetilde{k}_{L}$ there exists a level of supervisory effort $\widehat{e}(k)$ such that $\left.\Pi\left(\widetilde{q}_{L}\right)\right|_{k<\widetilde{k}_{L}}=\left.\Pi(\widehat{q})\right|_{k<\widetilde{k}_{L}}$, where $\left.\Pi\left(\widetilde{q}_{L}\right)\right|_{k<\widetilde{k}_{L}}$ and $\left.\Pi(\widehat{q})\right|_{k<\widetilde{k}_{L}}$ are given by (9) and (10), respectively.

Viewed this way, we can now write the bank's reaction function $\widehat{q}_{L}(k, e)$ at the individual bank level in the case of a local supervisor as

$$
\widehat{q}_{L}(k, e)=\left\{\begin{array}{c}
\widehat{q}(k) \text { for } e<\widehat{e}(k) \text { and } k<\widetilde{k}_{L} \\
\widetilde{q}_{L}(k) \text { for } e \geq \widehat{e}(k) \text { and } k<\widetilde{k}_{L} \\
\widehat{q}(k)>\widetilde{q}_{L}(k) \text { for } k \geq \widetilde{k}_{L},
\end{array}\right.
$$

where $\widehat{q}(k)$ is as in $(1)$ and $\widetilde{q}_{L}(k)$ is given by (6). Thus, a bank with capital $k>\widetilde{k}_{L}$ is not affected by the threat of regulatory intervention and will always choose its laissez-faire portfolio, while a bank with capital $k<\widetilde{k}_{L}$ will choose its laissez-faire portfolio level only if the supervisor exerts a level of effort below $\widehat{e}(k)$, and will meet the supervisory standard $\widetilde{q}_{L}(k)$ for $e>\widehat{e}(k)$. Note that, relative to more capitalized banks, less capitalized banks have riskier laissez faire portfolios (lower $\widehat{q}$ ) but are forced into safer portfolios of quality $\widetilde{q}_{L}$ once supervised.

Figure 2 represents graphically the relationship between bank portfolio choice, $\widehat{q}_{L}$, and supervisory effort, $e$, for banks with $k<\widetilde{k}_{L}$, for two different levels of capital, $k_{1}$ and $k_{2}$. For $e<\widehat{e}\left(k_{i}\right), i=1,2, \widehat{q}_{L}=\widehat{q}$. At $e=\widehat{e}\left(k_{i}\right)$, the bank with capital $k_{i}$ switches to the higher quality portfolio $\widetilde{q}_{L}$. Since $k_{1}<k_{2}$, we also have that $\widetilde{q}_{L}\left(k_{1}\right)>\widetilde{q}_{L}\left(k_{2}\right)$, reflecting our argument above that the supervisor is more lenient with better capitalized banks. 


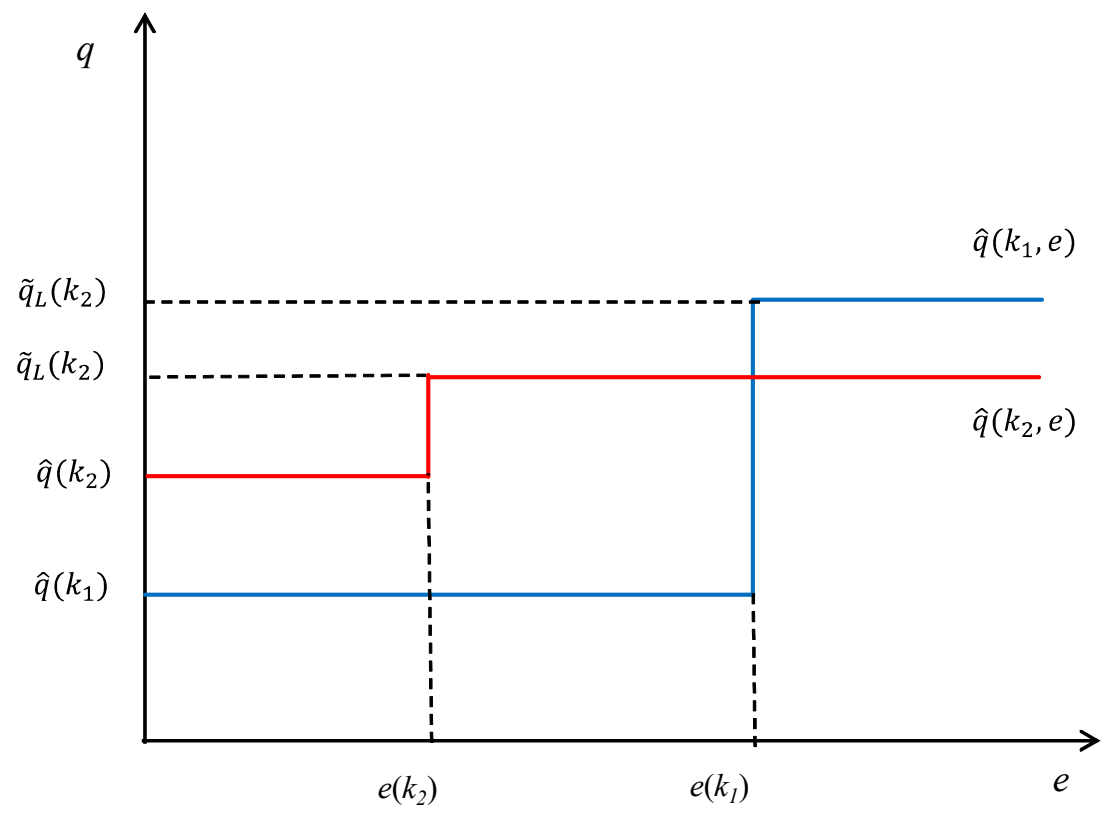

Figure 2: Bank's portfolio choice $q$ as a function of the supervisory effort $e$, for given levels of capital $k_{1}$ and $k_{2}$, with $k_{2}>k_{1}$.

Having derived the bank portfolio choice as a function of the supervisory effort $e$, we can now turn to study the supervisor's optimal effort choice as a function of the distribution of bank capital $F($.$) . Before doing this, we note that although we have derived it$ as an individual bank's choice, the threshold $\bar{k}_{L}(e)$ described in Lemma 1 can be seen as characterizing the set of banks that will be intervened if discovered by the supervisor (those with $k<\bar{k}_{L}(e)$ ) as well as those whose behavior will be affected by supervision (those with $\left.k \in\left[\bar{k}_{L}(e), \widetilde{k}_{L}\right)\right)$. In this sense, the threshold $\bar{k}_{L}(e)$ can be viewed as an aggregate reaction function to the supervisory effort $e$, with $\frac{d \bar{k}_{L}(e)}{d e}<0$, as argued above. In other words, the banking system's reaction function for the critical value $\bar{k}_{L}$ is downward sloping in $e$.

\subsection{Inspection effort of the supervisor}

We now turn to the local supervisor choice of effort $e$ to exert to inspect the bank. Given the decision to intervene for banks whose portfolio quality $q(k)$ is lower than the risk-based 
standard $\widetilde{q}_{L}(k)$, the supervisor's objective function is

$$
\begin{aligned}
\max _{e} S W_{L} & =\operatorname{Pr}\left(q>\widetilde{q}_{L}\right) E\left[q\left(R-\frac{1}{2} c q-(1-k)\right)-(1-q)(1-k) \psi_{L}-k \mid q>\widetilde{q}_{L}\right] \\
& +e \eta \operatorname{Pr}\left(q<\widetilde{q}_{L}\right) E\left[-A_{L}+q_{L}^{*}\left(R-\frac{1}{2} c q_{L}^{*}-(1-k)\right)-\left(1-q_{L}^{*}\right)(1-k) \psi_{L}-k \mid q<\widetilde{q}_{L}\right] \\
& +(1-e \eta) \operatorname{Pr}\left(q<\widetilde{q}_{L}\right) E\left[q\left(R-\frac{1}{2} c q-(1-k)\right)-(1-q)(1-k) \psi_{L}-k \mid q<\widetilde{q}_{L}\right]-\frac{d}{2} e^{2}
\end{aligned}
$$

where $\widetilde{q}_{L}<q_{L}^{*}$ is the intervention threshold as given in (6) and $q_{L}^{*}$ is the portfolio the supervisor implements upon successful intervention, as given by (4). The first term represents the expected total surplus when the bank chooses an investment portfolio of quality $q>\widetilde{q}_{L}$ and is allowed to continue. The second term represents the case when the supervisor inspects the bank, intervenes it and implements the portfolio $q_{L}^{*}$. The third term is the payoff when the supervisor is unsuccessful in her inspection or intervention and the bank can continue its investment project despite having chosen a portfolio with $q<\widetilde{q}_{L}$. Finally, the last term represents the cost of inspection.

For simplicity we can rewrite the supervisor's objective function as

$S W_{L}=E\left[q\left(R-\frac{1}{2} c q-(1-k)\right)-(1-q)(1-k) \psi_{L}-k\right]+e \operatorname{Pr}\left(q<\widetilde{q}_{L}\right) E\left[I_{L}\left(q_{L}^{*}, q, k\right) \mid q<\widetilde{q}_{L}\right]-\frac{d}{2} e^{2}$

where, as defined in $(5), I_{L}\left(q_{L}^{*}, q, k\right)$ is the net gain from intervention for the supervisor. Clearly, only the last two terms depend on the supervisor's inspection effort. This means that the supervisor will choose the inspection effort taking into account that this will affect only banks with portfolios of quality $q<\widetilde{q}_{L}$ or, equivalently, those with $k<\bar{k}_{L}(e)$ as defined in Lemma 1. We can then derive the supervisor's optimal effort as follows.

Lemma 2 Given the bank's optimal behavior as described in Lemma 1, the local supervisor chooses a level of effort $e_{L}\left(\bar{k}_{L}\right)$ given by

$$
e_{L}\left(\bar{k}_{L}\right)=\int_{0}^{\bar{k}_{L}} I_{L}\left(q_{L}^{*}, \widehat{q}, k\right) f(k) d k<\bar{e}_{L} .
$$

It follows that $\frac{\partial e_{L}\left(\bar{k}_{L}\right)}{\partial \bar{k}_{L}}>0$. 
The lemma describes the supervisor's reaction function in the case of local supervision. The supervisory effort depends positively on the threshold $\bar{k}_{L}$ characterizing banks' behavior. The higher $\bar{k}_{L}$, the greater the fraction of banks with $k<\bar{k}_{L}$ that will choose to be excessively risky relative to their level of capital (i.e, $\widehat{q}(k)<\widetilde{q}_{L}(k)$ ), and therefore the higher the supervisory effort.

\subsection{Equilibrium}

Having characterized the reaction functions for the supervisor and the banks, we can now characterize the equilibrium.

Proposition 2 For given intervention cost $A_{L}$ and per dollar cost of bank failure $\psi_{L}$, there is a unique equilibrium $\left(e_{L}^{*}, \bar{k}_{L}^{*}, \widetilde{q}_{L}, \widehat{q}_{L}\right)$ in supervisory effort, intervention strategy, and bank portfolio choices such that:

1) The supervisor will intervene (upon obtaining actionable information) any bank with $q<\widetilde{q}_{L}(k)$, where $\widetilde{q}_{L}(k)$ is as in (6);

2) Banks that choose not to meet the supervisor's standards $\widetilde{q}_{L}(k)$ choose their laissezfaire optimal portfolios $\widehat{q}(k)$;

3) The optimal supervisory effort $e_{L}^{*}$ and capital threshold $\bar{k}_{L}^{*}$ below which banks choose not to meet supervisory standards satisfy: $e_{L}\left(\bar{k}_{L}^{*}\right)=e_{L}^{*}$ and $\bar{k}_{L}\left(e_{L}^{*}\right)=\bar{k}_{L}^{*}$.

Proposition 2 establishes that a unique equilibrium exists where the supervisor exerts a strictly positive level of effort in identifying which banks may have portfolios that she views as excessively risky, and some (but not all) banks adjust their behavior to conform to the supervisory standards.

Figure 3 illustrates the proposition. The downward sloping line represents the banks' reaction function, $\bar{k}_{L}(e)$, as a function of supervisory effort. The upward sloping line represents the supervisor's reaction function $e_{L}(\bar{k})$ as a function of the threshold level of capital below which banks choose their laissez-faire portfolios. The point where they intersect is the equilibrium, and implies a strictly positive level of effort, $e_{L}^{*}$, as well as a threshold level of capital $\bar{k}_{L}^{*}$ strictly less than $\widetilde{k}_{L}$, meaning that supervision leads a strictly positive mea- 


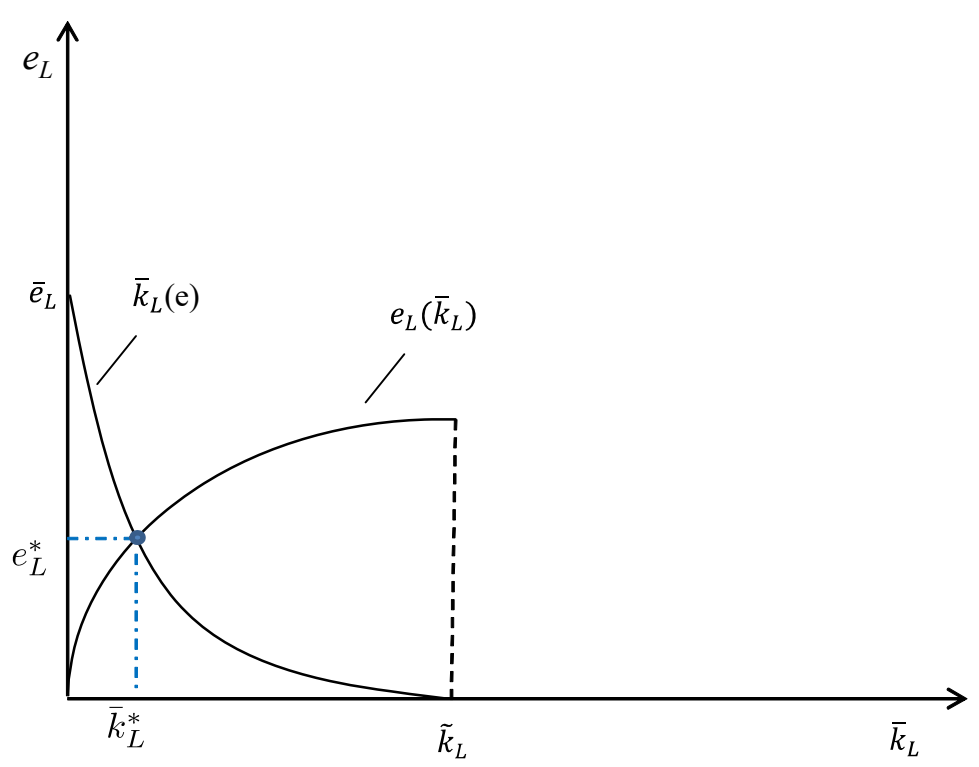

Figure 3: Equilibrium with local supervision. The figure describes the bank's reaction function $\bar{k}_{L}(e)$ and the local supervisor's reaction function $e_{L}\left(\bar{k}_{L}\right)$ as functions of supervisory effort $e_{L}$ and capital threshold $\bar{k}_{L}$, respectively.

sure of banks to move away from their most preferred portfolio $\widehat{q}$ and instead adhere to the regulatory standard $\widetilde{q}_{L}$.

\section{The centralization of bank supervision}

So far, we have considered the case where there is only a single, local supervisor, and analyzed a model of bank supervision where the supervisor's inspection and intervention decisions have implications for the bank's choice of portfolio risk relative to its capitalization. Here, we introduce a central supervisor who has the power to mandate intervention but must rely on the local agency to obtain actionable information before she can intervene.

Consider therefore the following extension to the model. A central supervisor has interest in maintaining a healthy banking sector and minimizing the need for costly intervention, much as the local regulator, but faces somewhat different trade-offs. In particular, the central supervisor perceives the cost of intervention as $A_{C} \neq A_{L}$ and/or the cost of bank failure as $\psi_{C} \neq \psi_{L}$, so that it is more/less willing to intervene than the local regulator.

This difference in the perceived costs may represent the central supervisor's internaliza- 
tion of bank failures on the overall financially integrated area, or may simply reflect that the local supervisor is partially "captured" by local constituents, including banks, while the central supervisor is less likely to attach much weight to local political economy considerations. Regardless, the implication is that the central supervisor may mandate intervention by the local supervisor in situations where the local supervisor would prefer to forbear and allow the bank to operate unimpeded, or vice versa. The rest of the model remains unchanged.

We can now study the central supervisor's intervention decision. As in Section 4.1, if the local supervisor successfully obtained information about a given bank's portfolio, the central supervisor must decide whether it is optimal to intervene the bank or not. The central supervisor compares intervening, which, if successful, entails the cost $A_{C}$ but gives a payoff equal to

$$
\begin{aligned}
& \eta\left(-A_{C}+q_{C}^{*}\left(R-\frac{1}{2} c q_{C}^{*}-(1-k)\right)-\left(1-q_{C}^{*}\right)(1-k) \psi_{C}-k\right) \\
& +(1-\eta)\left(q\left(R-\frac{1}{2} c q-(1-k)\right)-(1-q)(1-k) \psi_{C}-k\right)
\end{aligned}
$$

where

$$
q_{C}^{*}=\frac{R+(1-k)\left(\psi_{C}-1\right)}{c}
$$

is the central supervisor's preferred bank portfolio conditional on intervention, and allowing the bank to continue with its initial portfolio choice $q$, which gives the supervisor a payoff equal to

$$
q\left(R-\frac{1}{2} c q-(1-k)\right)-(1-q)(1-k) \psi_{C}-k .
$$

It is straightforward to see that the comparison is the same as that in (5), only with a different intervention cost $A_{C}$ and per dollar cost of bank failure $\psi_{C}$. Therefore, following the analysis in Section 4.1, we can define the difference between (16) and (17) as

$$
\begin{aligned}
I_{C}\left(q_{C}^{*}, q, k\right) & =\eta\left(-A_{C}+q_{C}^{*}\left(R-\frac{1}{2} c q_{C}^{*}-(1-k)\right)-\left(1-q_{C}^{*}\right)(1-k) \psi_{C}\right) \\
& -\eta\left(q\left(R-\frac{1}{2} c q-(1-k)\right)-(1-q)(1-k) \psi_{C}\right),
\end{aligned}
$$

and find the optimal intervention threshold for the central supervisor below which intervention will occur as given by

$$
\widetilde{q}_{C}(k)=\frac{1}{c}\left(R+(1-k)\left(\psi_{C}-1\right)-\sqrt{2 c A_{C}}\right) .
$$


It is worth noting that, as for the case of local supervision, $\widetilde{q}_{C}(k)$ represents a subgame perfect solution when the central supervisor cannot precommit to an intervention threshold involving a time inconsistency. As in the previous section, we assume $\widetilde{q}_{C}(k)$ to be positive at least for some values of $k$, for which assuming that $\psi_{C}>\sqrt{2 c A_{C}}$ is sufficient.

The relative positions of the intervention thresholds $\widetilde{q}_{C}(k)$ and $\widetilde{q}_{L}(k)$ of the central and local supervisor, respectively, will depend on the relative magnitude of the parameters that determine the cost of intervention and eventual deposit insurance outlays: $A_{C}, A_{L}, \psi_{C}$, and $\psi_{L}$. Any $\widetilde{q}_{C} \neq \widetilde{q}_{L}$ may entail inefficient information collection by the local regulator, but the nature of the inefficiency may be different depending on whether $\widetilde{q}_{C}>\widetilde{q}_{L}$ or $\widetilde{q}_{C}<\widetilde{q}_{L}$, that is, on whether the central supervisor is tougher or more lenient than the local one. Looking at the expressions in (6) and (19) gives the following immediate result.

Lemma 3 (1) Assume that $\psi_{C}=\psi_{L}$, so that both supervisors bear the same per dollar failure cost. Then, the central supervisor is tougher in her intervention policy than the local supervisor if she faces a lower intervention cost (i.e., $\widetilde{q}_{C}(k)>\widetilde{q}_{L}(k)$ if $A_{C}<A_{L}$ ), and is more lenient otherwise. (2) Assume that $A_{C}=A_{L}$, so that both supervisors bear the same cost of intervention. Then, the central supervisor is tougher if she faces a higher shadow cost of funds, i.e., $\widetilde{q}_{C}(k)>\widetilde{q}_{L}(k)$ if $\psi_{C}>\psi_{L}$, and is more lenient otherwise.

Note that the case where $\psi_{C}>\psi_{L}$ implies also that the central supervisor will choose, upon intervention, a higher portfolio quality for the bank than the local supervisor, i.e., $q_{C}^{*}>q_{L}^{*}$. The intuition is simple: If the central supervisor internalizes a higher cost when a bank fails, she will want to prevent bank failure more than the local supervisor and will therefore choose to implement a higher portfolio quality upon intervention.

In what follows, we focus on the case where the central supervisor is tougher and we analyze the implications this has for bank risk taking and supervisory effort in equilibrium. This focus reflects one of the main rationales for the centralization of supervision: local supervisors are deemed to be too lenient and unwilling to intervene their (local) banks (Agarwal et al., 2014), and centralization is designed to introduce tougher standards and put a larger focus on measures such as prompt corrective action, which reduces the amount 
of discretion local supervisors may have. Per Lemma 3, in the context of the model a tougher central supervisor simply means that either $A_{C}<A_{L}$ or $\psi_{C}>\psi_{L}$, or both.

\subsection{An unambiguously tougher central supervisor}

Assume that the central regulator has a tougher intervention policy, $\widetilde{q}_{C}(k)>\widetilde{q}_{L}(k)$, either because of a lower intervention cost $A_{C}<A_{L}$ or because she bears a higher cost of failure, $\psi_{C}>\psi_{L}$. We can now turn to the bank's portfolio decision choice and the supervisory effort, which is undertaken by the local supervisor. The analysis follows similar steps to those in the case of the local supervisor.

To see how the threat of regulatory intervention affects banks' portfolio choice, we first find the threshold $\widetilde{k}_{C}$ at which a bank independently would choose a portfolio $\widehat{q}(k)$ which is sufficiently safe not to be intervened given its level of capital: $\widehat{q}(k)=\widetilde{q}_{C}(k)$. Equating (1) and (19) and solving for $k$ gives

$$
\widetilde{k}_{C}=\left(1-\frac{1}{\psi_{C}} \sqrt{2 c A_{C}}\right) .
$$

Again, we assume that $\widetilde{k}_{C}>0$, which is true if $\psi_{C}>\sqrt{2 c A_{C}}$. Note also that $\widetilde{k}_{C}>\widetilde{k}_{L}$ if either $\psi_{C}>\psi_{L}$ or $A_{C}<A_{L}$. This means that, when the central supervisor is tougher, banks are less likely to choose voluntarily a portfolio sufficiently safe to satisfy the supervisory standards, i.e., a portfolio of quality $q$ at least equal to the supervisory risk-based intervention threshold $\widetilde{q}_{C}(k)$.

We can now see how the threat of intervention affects the choice of banks with capital below the threshold $\widetilde{k}_{C}$. Following the same analysis as in Section 4.2, we obtain the following.

Lemma 4 For a given level of supervisory effort e, there exists a level of capital $\bar{k}_{C}(e)$ such that banks with $k<\bar{k}_{C}(e)$ choose the laissez-faire portfolio quality $\widehat{q}(k)$, while banks with $k \in\left[\bar{k}_{C}(e), \widetilde{k}_{C}\right]$ switch to a portfolio of quality $\widetilde{q}_{C}(k)>\widehat{q}(k)$, where

$$
\bar{k}_{C}(e)=\left(1-\frac{R \sqrt{e \eta}+\sqrt{2 c A_{C}}}{\psi_{C}+\sqrt{e \eta}}\right)<\widetilde{k}_{C} .
$$

It follows that $\frac{\partial \bar{k}_{C}(e)}{\partial e}<0, \frac{\partial \bar{k}_{C}(e)}{\partial \psi_{C}}>0$ and $\frac{\partial \bar{k}_{C}(e)}{\partial A_{C}}<0$. 
The lemma identifies the banks whose portfolio choice is affected by the threat of intervention when a central supervisor is present. As in Section 4.2 , the function $\bar{k}_{C}(e)$ can in fact be seen both as an individual bank's reaction function for given supervisory effort $e$ and as an aggregate reaction function characterizing the proportion of banks with $k<\bar{k}_{C}(e)$ that will be intervened if discovered and those with $k \in\left[\bar{k}_{C}(e), \widetilde{k}_{C}\right)$ whose portfolio choice is affected by supervision.

As before, for the supervisory intervention to be meaningful, we assume that $\bar{k}_{C}(e)>0$. Setting (21) equal to zero and solving for $e$, this means requiring the parameters $R, \psi_{C}$ and $A_{C}$ are such that in equilibrium the local supervisor will choose an inspection effort $e<\bar{e}_{C}$, where

$$
\bar{e}_{C}=\frac{\left(\psi_{C}-\sqrt{2 c A_{C}}\right)^{2}}{\eta(R-1)^{2}} .
$$

Comparing the expressions for $\bar{k}_{C}(e)$ and $\bar{k}_{L}(e)$ as in (21) and (11), we obtain the following result.

Lemma 5 If the central supervisor is tougher than the local supervisor, i.e., if $A_{C}<A_{L}$ for $\psi_{C}=\psi_{L}$, or if $\psi_{C}>\psi_{L}$ for $A_{C}=A_{L}$, so that $\widetilde{q}_{C}(k)>\widetilde{q}_{L}(k)$, then the banks' reaction function $\bar{k}_{C}(e)$ lies above the reaction function under independence: $\bar{k}_{C}(e)>\bar{k}_{L}(e)$ for all e.

The lemma establishes that, for a given supervisory effort $e, \bar{k}_{C}(e)>\bar{k}_{L}(e)$, meaning that there will be banks with capital $k \in\left(\bar{k}_{L}(e), \bar{k}_{C}(e)\right]$ that will no longer comply with the minimum supervisory portfolio quality under centralised supervision and will therefore risk being intervened. Put differently, as standards get tougher, absent increased regulatory effort, there will be fewer banks that meet the minimum requirements. This, however, does not mean that there are fewer banks that alter their behavior in response to regulation since it is also the case that $\widetilde{k}_{C}>\widetilde{k}_{L}$.

To examine when the supervisory threat has a greater effect on banks' behavior, we compare $\widetilde{k}_{C}-\bar{k}_{C}(e)$ with $\widetilde{k}_{L}-\bar{k}_{L}(e)$, the range of banks who deviate from their preferred portfolios to avoid being intervened under centralization and under local supervision, respectively. Substituting all the relevant expressions, we have

$$
\widetilde{k}_{C}-\bar{k}_{C}(e)=\frac{\sqrt{e \eta}\left(R \psi_{C}-\sqrt{2 c A_{C}}\right)}{\psi_{C}\left(\psi_{C}+\sqrt{e \eta}\right)}
$$


and

$$
\widetilde{k}_{L}-\bar{k}_{L}(e)=\frac{\sqrt{e \eta}\left(R \psi_{L}-\sqrt{2 c A_{L}}\right)}{\psi_{L}\left(\psi_{L}+\sqrt{e \eta}\right)} .
$$

For the case where both supervisors bear the same failure cost $\psi_{C}=\psi_{L}$, but the central supervisor has a lower cost of intervention, $A_{C}<A_{L}$, the expressions above show that $\widetilde{k}_{C}-\bar{k}_{C}(e)>\widetilde{k}_{L}-\bar{k}_{L}(e)$. This means that more banks adjust their portfolios for the threat of supervisory intervention under centralized supervision than under local supervision.

Given the bank's portfolio choice for a given level of supervisory effort $e$, we can now study the local supervisor's effort problem when the central supervisor decides whether to intervene or not, but must rely on the information collected by the local supervisor in order to act. In the case when she was acting independently, the local supervisor's effort problem was given by (14). Essentially, the intervention decision of the local supervisor, $\widetilde{q}_{L}$, partitioned the mass of banks into two regions, and effort was a function of the mass of banks with $q<\widetilde{q}_{L}$ and the average benefit from intervention in that region, $E\left[I_{L}\left(q_{L}^{*}, q, k\right) \mid q<\widetilde{q}_{L}\right]$, where $I_{L}\left(q_{L}^{*}, q, k\right)$ is given by $(5)$. Here, however, since the two supervisors have different intervention thresholds $\left(\widetilde{q}_{C}>\widetilde{q}_{L}\right)$, there may be a region where the supervisor's effort is in fact decreasing in the set of banks that are subject to being intervened. This is because, for banks in the interval $\left(\widetilde{q}_{L}, \widetilde{q}_{C}\right)$, the local supervisor is against intervention and intervention can only occur when information is collected. Moreover, to the extent that the portfolio quality that will be implemented upon intervention, $q_{C}^{*}$, is different under centralization than under independence, $q_{L}^{*}$, the local supervisor's incentives to exert effort will be reduced further.

The arguments above imply that when the central supervisor is tougher than the local one, banks will be partitioned into three groups. The first group consists of the most highly capitalized banks, who find it optimal to choose $q \geq \widetilde{q}_{C}$. For this group, the local supervisor obtains no benefits from learning a bank's balance sheet $(q, k)$ as these banks will not be intervened.

The second group comprises the least capitalized banks. Learning about these banks' balance sheets brings a net benefit to the local supervisor. If $q_{C}^{*}=q_{L}^{*}$, the threshold portfolio quality for this group is $q<\widetilde{q}_{L}$, which is the same as for the banks that would be intervened even under independent local supervision. However, if $q_{C}^{*} \neq q_{L}^{*}$ the threshold is lower: 
the local supervisor's benefits from intervention are lower since $q_{C}^{*}$ instead of $q_{L}^{*}$ will be implemented upon intervention. Put differently, for banks with $\widehat{q}$ close to $\widetilde{q}_{L}$, the local supervisor will incur a loss (recall that $\widehat{q}=\widetilde{q}_{L}$ is the point where the local supervisor is exactly indifferent between intervening and not when intervention calls for choosing the portfolio $q_{L}^{*}$ ). We define the point at which the local supervisor is indifferent between intervention and not under centralized supervision as $\widetilde{q}\left(q_{C}^{*}\right)$, and note that $\widetilde{q}\left(q_{C}^{*}\right)=\widetilde{q}_{L}$ when $q_{C}^{*}=q_{L}^{*}$.

Finally, the third group consists of banks with "intermediate" capitalization (those choosing $\left.q \in\left[\widetilde{q}\left(q_{C}^{*}\right), \widetilde{q}_{C}\right)\right)$. Learning the bank's type entails a loss for the local supervisor since she would rather let these banks continue than intervene them. But once information about their balance sheet is obtained, the central supervisor forces intervention. The loss is given by the difference between the intervention and no intervention payoffs for the local supervisor when the central supervisor implements $q_{C}^{*}$. Formally, this loss, denoted as $I_{L}\left(q_{C}^{*}, q, k\right)$, is given by the same expression as in (5) once $q_{L}^{*}$ is replaced with $q_{C}^{*}$.

The argument above implies that now the local supervisor's problem is to choose the effort that maximizes her total return $S W_{L}^{C}$ under centralization as given by

$$
\begin{aligned}
& \max _{e} S W_{L}=\operatorname{Pr}\left(q>\widetilde{q}_{C}\right) E\left[q\left(R-\frac{1}{2} c q-(1-k)\right)-(1-q)(1-k) \psi_{L}-k \mid q>\widetilde{q}_{C}\right] \\
& +e \eta \operatorname{Pr}\left(q<\widetilde{q}\left(q_{C}^{*}\right)\right) E\left[-A_{L}+q_{C}^{*}\left(R-\frac{1}{2} c q_{C}^{*}-(1-k)\right)-\left(1-q_{C}^{*}\right)(1-k) \psi_{L}-k \mid q<\widetilde{q}\left(q_{C}^{*}\right)\right] \\
& +e \eta \operatorname{Pr}\left(\widetilde{q}\left(q_{C}^{*}\right) \leq q<\widetilde{q}_{C}\right) E\left[-A_{L}+q_{C}^{*}\left(R-\frac{1}{2} c q_{C}^{*}-(1-k)\right)-\left(1-q_{C}^{*}\right)(1-k) \psi_{L}-k \mid \widetilde{q}\left(q_{C}^{*}\right) \leq q<\widetilde{q}_{C}\right] \\
& \quad(1-e \eta) \operatorname{Pr}\left(q<\widetilde{q}\left(q_{C}^{*}\right)\right) E\left[q\left(R-\frac{1}{2} c q-(1-k)\right)-(1-q)(1-k) \psi_{L}-k \mid q<\widetilde{q}\left(q_{C}^{*}\right)\right] \\
& +(1-e \eta) \operatorname{Pr}\left(\widetilde{q}\left(q_{C}^{*}\right) \leq q<\widetilde{q}_{C}\right) E\left[q\left(R-\frac{1}{2} c q-(1-e)\right)-(1-q)(1-k) \psi_{L}-k \mid \widetilde{q}\left(q_{C}^{*}\right) \leq q<\widetilde{q}_{C}\right]-\frac{d}{2} e^{2}
\end{aligned}
$$

The above expression reduces to

$$
\begin{gathered}
\max _{e} S W_{L}=E\left[q\left(R-\frac{1}{2} c q-(1-k)\right)-(1-q)(1-k)-k\right] \\
+e \operatorname{Pr}\left(q<\widetilde{q}\left(q_{C}^{*}\right)\right) E\left[I_{L}\left(q_{C}^{*}, q, k\right) \mid q<\widetilde{q}\left(q_{C}^{*}\right)\right] \\
+e \operatorname{Pr}\left(\widetilde{q}\left(q_{C}^{*}\right) \leq q<\widetilde{q}_{C}\right) E\left[I_{L}\left(q_{C}^{*}, q, k\right) \mid \widetilde{q}\left(q_{C}^{*}\right) \leq q<\widetilde{q}_{C}\right]-\frac{d}{2} e^{2},
\end{gathered}
$$

where the expression $I_{L}\left(q_{C}^{*}, q, k\right)$, as given in (5) but with $q_{C}^{*}$ instead of $q_{L}^{*}$, indicates now the 
difference between the intervention and the no intervention payoffs for the local supervisor under centralization.

Given that $E\left[I_{L}\left(q_{C}^{*}, q, k\right) \mid q<\widetilde{q}\left(q_{C}^{*}\right)\right]<E\left[I_{L}\left(q_{L}^{*}, q, k\right) \mid q<\widetilde{q}\left(q_{C}^{*}\right)\right]$ if $q_{C}^{*} \neq q_{L}^{*}$ and $E\left[I_{L}\left(q_{C}^{*}, q, k\right) \mid \widetilde{q}\left(q_{C}^{*}\right) \leq q<\widetilde{q}_{C}\right]<0$, the expression for $S W_{L}$ above is smaller than the expression for $S W_{L}$ in (14). Analogously to above, we define $\widetilde{k}\left(q_{C}^{*}\right)$ as the value of $k$ for which $\widehat{q}(k)=\widetilde{q}\left(q_{C}^{*}\right)$. Assuming that the banks behave as above, choosing either $\widehat{q}$ or $\widetilde{q}_{C}$, we obtain the following.

Lemma 6 If the central regulator is tougher than the local regulator, that is if $A_{C}<A_{L}$ for $\psi_{C}=\psi_{L}$, or if $\psi_{C}>\psi_{L}$ for $A_{C}=A_{L}$ so that $\widetilde{q}_{C}(k)>\widetilde{q}_{L}(k)$ and $q_{C}^{*} \geq q_{L}^{*}$, the local supervisor's reaction function, as given by

$$
e_{C}\left(\bar{k}_{C}\right)=\int_{0}^{\min \left(\bar{k}_{C}, \widetilde{k}\left(q_{C}^{*}\right)\right)} I_{L}\left(q_{C}^{*}, \widehat{q}, k\right) f(k) d k+\mathbf{1}_{\bar{k}_{C}>\widetilde{k}\left(q_{C}^{*}\right)} \int_{\widetilde{k}\left(q_{C}^{*}\right)}^{\bar{k}_{C}} I_{L}\left(q_{C}^{*}, \widehat{q}, k\right) f(k) d k<\bar{e}_{C},
$$

lies (weakly) below the reaction function under independence: $e_{C}(\bar{k}) \leq e_{L}(\bar{k})$.

The lemma characterizes the local supervisor's reaction function under central supervision. As it shows, we can decompose the reaction function as

$$
e_{C}=\left\{\begin{array}{l}
\int_{0}^{\bar{k}_{C}} I_{L}\left(q_{C}^{*}, \widehat{q}, k\right) f(k) d k \text { for } \bar{k}_{C} \leq \widetilde{k}\left(q_{C}^{*}\right) \\
\int_{0}^{\widetilde{k}\left(q_{C}^{*}\right)} I_{L}\left(q_{C}^{*}, \widehat{q}, k\right) f(k) d k+\int_{\widetilde{k}\left(q_{C}^{*}\right)}^{\bar{k}_{C}} I_{L}\left(q_{C}^{*}, \widehat{q}, k\right) f(k) d k \text { for } \bar{k}_{C}>\widetilde{k}\left(q_{C}^{*}\right),
\end{array}\right.
$$

where $I_{L}\left(q_{C}^{*}, \widehat{q}, k\right)>0$ for $\bar{k}_{C} \leq \widetilde{k}\left(q_{C}^{*}\right)$ and $I_{L}\left(q_{C}^{*}, \widehat{q}, k\right)<0$ for $\bar{k}_{C}>\widetilde{k}\left(q_{C}^{*}\right)$. Given that

$$
\frac{\partial e_{C}}{\partial \bar{k}_{C}}=\left\{\begin{array}{l}
I_{L}\left(q_{C}^{*}, \widehat{q}, \bar{k}_{C}\right) f\left(\bar{k}_{C}\right) \text { for } \bar{k}_{C} \leq \widetilde{k}\left(q_{C}^{*}\right) \\
I_{L}\left(q_{C}^{*}, \widehat{q}, \bar{k}_{C}\right) f\left(\bar{k}_{C}\right) \text { for } \bar{k}_{C}>\widetilde{k}\left(q_{C}^{*}\right)
\end{array}\right.
$$

it follows that the reaction function $e_{C}\left(\bar{k}_{C}\right)$ is positively sloped for $\bar{k}_{C} \leq \widetilde{k}\left(q_{C}^{*}\right)$ and negatively sloped for $\bar{k}_{C}>\widetilde{k}\left(q_{C}^{*}\right)$.

The lemma establishes that, for a given $\bar{k}_{C}$, when supervisory powers are centralized, the local supervisor will be, all things equal, (weakly) less diligent in trying to uncover risk taking on the side of the banks under her jurisdiction. This occurs for the simple reason that once any hard information is uncovered, the central supervisor can use that to intervene if the bank is discovered to have chosen a riskier portfolio than what the supervisor desires. 
In some of these instances, the local supervisor would prefer not to intervene because she faces a larger intervention cost relative to the benefit she perceives from adjusting the bank's portfolio. As a consequence, the local supervisor chooses to reduce the likelihood that any damning evidence is found, meaning that she reduces her effort relative to what she would do if she had full control over bank supervision and intervention choice.

Having characterized the reaction function $\bar{k}_{C}(e)$ of the banks and that of the supervisor $e_{C}\left(\bar{k}_{C}\right)$, we can now turn to characterize the equilibrium. For exposition, we distinguish the analysis into two cases: the case where the central regulator has lower intervention cost than the local regulator $\left(A_{C}<A_{L}\right)$ but equal costs of bank failure $\left(\psi_{C}=\psi_{L}\right)$, and the case where the central regulator has higher failure cost than the local regulator $\left(\psi_{C}>\psi_{L}\right)$ but equal intervention cost $\left(A_{C}=A_{L}\right)$. In both cases the central regulator is tougher in that she intervenes at a higher level of portfolio quality, $\widetilde{q}_{C}>\widetilde{q}_{L}$, than the local regulator. However, in the former case $q_{C}^{*}=q_{L}^{*}$ so that the supervisory portfolio quality does not vary with centralized supervision, while in the latter $q_{C}^{*}>q_{L}^{*}$. This affects the equilibrium values $\left(e_{C}^{*}, \bar{k}_{C}^{*}\right)$ differently as we will see below.

In both cases we analyze below, we focus on understanding the effect of centralization of supervision on the local supervisor's inspection effort and risk in the banking sector. To capture the latter, we define two measures of banks' portfolio quality. The first is the average portfolio quality $q$ chosen by banks under each regulatory regime:

$$
Q_{j}=\int_{0}^{1} \widehat{q}(k) f(k) d k+\int_{\bar{k}_{I}}^{\widetilde{k}_{I}}\left[\widetilde{q}_{I}(k)-\widehat{q}(k)\right] f(k) d k,
$$

while the second is the average portfolio quality $q$ expected to prevail after the regulatory intervention:

$$
Q_{j}^{*}=\int_{0}^{1} \widehat{q}(k) f(k) d k+\int_{\bar{k} j}^{\widetilde{k} j}\left[\widetilde{q}_{j}(k)-\widehat{q}(k)\right] f(k) d k+e_{j}^{*} \eta \int_{0}^{\bar{k}_{I}}\left[q_{j}^{*}(k)-\widehat{q}(k)\right] f(k) d k,
$$

where $j=L, C$. Therefore, $Q_{J}$ may be viewed as an ex ante measure of portfolio risk, whereas $Q_{J}^{*}$ is an ex post measure. 


\subsection{Lower intervention cost for the central supervisor: $A_{C}<A_{L}$ and $\psi_{C}=\psi_{L}$}

We start with the case where $A_{C}<A_{L}$ and $\psi_{C}=\psi_{L}$ so that the central supervisor is tougher because of a lower intervention threshold but chooses the same portfolio as the local supervisor conditional on intervention. Formally, this means $\widetilde{q}_{C}>\widetilde{q}_{L}$ but $q_{C}^{*}=q_{L}^{*}$. It follows from Lemmas 5 and 6 that the local supervisor's reaction function under centralization coincides with the one under local supervision as in (15) for $\bar{k}_{C} \leq \widetilde{k}_{L}$, while the bank's reaction function $\bar{k}_{C}(e)$ under centralization remains strictly above the one under local supervision $\bar{k}_{L}(e)$.

We can now analyze the equilibrium levels of the supervisory effort and banks' portfolio choices, as well as the equilibrium risk levels of the banking sector. We have the following result.

Proposition 3 Suppose that $\psi_{C}=\psi_{L}$. There is a value $\delta>0$ such that, for $0<A_{L}-$ $A_{C}<\delta$, the local supervisor exerts more effort under centralization than when independent, $e_{C}^{*}>e_{L}^{*}$, and banks' average portfolio quality is higher, both ex ante and ex post: $Q_{C}>Q_{L}$ and $Q_{C}^{*}>Q_{L}^{*}$.

The proposition establishes that when the conflict between the local and the central supervisor is relatively small, meaning that their respective costs of intervention are not very different, centralizing bank supervision leads to an increase in the effort exerted by the local supervisor in detecting banks' portfolio choices and consequently also leads to safer portfolios. The reason is that the tighter standards of the central supervisor require that banks choose safer portfolios to avoid being intervened, and some of them now find it too onerous to do so. The local supervisor, while not fully in agreement with the central supervisor, exerts more effort in order to try to catch the banks that would have behaved in the absence of a central supervisor, but now prefer to risk being intervened rather than meet the tougher standards. In other words, even though the tougher standards introduced by the central supervisor reduce the local supervisor's incentives to exert effort ceteris paribus, much as is the case in the literature on the delegation of authority (e.g., Aghion and Tirole, 


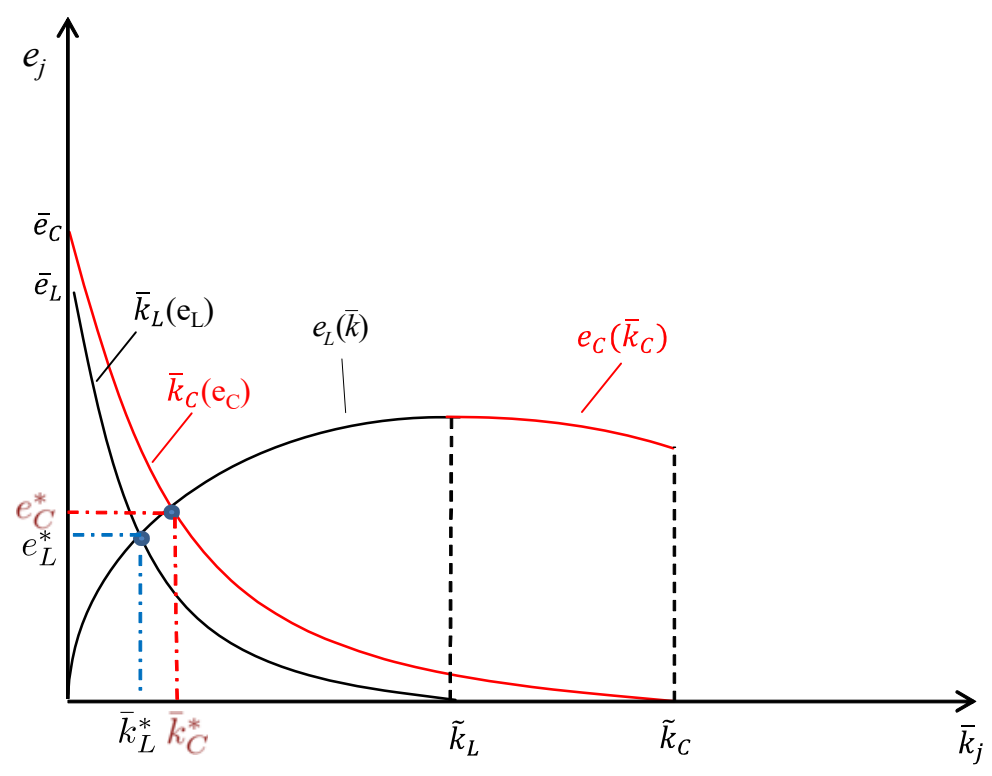

Figure 4: Equilibrium with centralized supervision in the case of a tougher central regulator. The figure describes the bank's reaction function $\bar{k}_{j}\left(e_{j}\right)$ and the local supervisor's reaction function $e_{j}\left(\bar{k}_{j}\right)$ as a function of supervisory effort $e_{j}$ and bank capital threshold $\bar{k}_{j}$, with $j=L, C$.

1997), the reaction by banks to the tougher standard acts as a countervailing force and push the local supervisor to in fact exert more effort in equilibrium. To the best of our knowledge, this aspect of supervisory regimes has not been studied before. This result is illustrated in Figure 4, which shows that it is the fact that banks' reaction function has shifted up that leads to greater inspection effort by the supervisor in equilibrium.

However, centralization of supervision creates an agency problem vis á vis the local supervisor who must collect actionable information about the banks' operations. This may lead to less diligence on the part of the local supervisor when the conflict with the central supervisor is sufficiently large.

To show when this happens, we first note that given a uniform distribution of bank capital, i.e., $k \sim U[0,1]$, the reaction function of the supervisor can be expressed as

$$
e_{j}(\bar{k})=\left(\frac{\left(2 \psi_{L}-\psi_{C}\right) \psi_{C}}{2 c}\left(\bar{k}_{j}-\bar{k}_{j}^{2}+\frac{\bar{k}_{j}^{3}}{3}\right)-\bar{k}_{j} A_{L}\right) \frac{\eta}{d},
$$


while the reaction function of the banks can be written explicitly as

$$
\bar{k}_{j}(e)=1-\frac{\left(R \sqrt{e_{j} \eta}+\sqrt{2 c A_{j}}\right)}{\left(\psi_{j}+\sqrt{e_{j} \eta}\right)}
$$

where $j=L, C$. We have the following result.

Proposition 4 Suppose that $\psi_{C}=\psi_{L}$ and $A_{C} \leq \frac{1}{8 c}\left(\sqrt{3\left(8 c A_{L}-\psi_{L}^{2}\right)}-\psi_{L}\right)^{2}$. Then, there exists an equilibrium under centralization which entails a supervisory effort $e_{C}^{*}=0, \bar{k}_{C}=\widetilde{k}_{C}$ and lower bank portfolio quality: $Q_{C}<Q_{L}$ and $Q_{C}^{*}<Q_{L}^{*}$.

As the divergence between the objectives of the central and the local supervisors increases, the local supervisor's incentives to exert effort decrease further. Over a certain region, as long as the reaction functions of the banks and of the supervisor intersect before the tangency point, there are multiple equilibria. In this case, there is at least one equilibrium with positive effort and one with zero effort. In the former, the effort level can be greater or lower than under (independent) local supervision, in which case, the bank's reaction function intersects the supervisor's reaction function in its downward sloping section. In the latter, the incentives of the local supervisor are sufficiently muted that no collection of information is optimal. The different equilibria cannot be Pareto-ranked since both the local and the central supervisor prefer the equilibrium with positive effort, whereas the banks always prefer the equilibrium with no effort and thus no chance of being intervened.

Notably, the parameter space for which equilibrium with zero inspection effort exists increases in $A_{L}$ and decreases with $\psi_{L}$; that is, it is unambiguously broader for laxer local supervisors. Intuitively, these are exactly the supervisors for whom the agency problem vis a vis the central supervisor is the greatest.

As the conflict between the local and the central supervisor increases further, the two reaction functions cross only beyond their tangency point. In this case, the equilibrium with $e_{C}^{*}=0$ and $\bar{k}_{C}=\widetilde{k}_{C}$ is the only surviving equilibrium. At this point, centralization of supervision reduces total output relative to local supervision since supervision is totally ineffective and banks simply choose their laissez-faire portfolio quality. This raises the question of whether the central regulator can improve over the subgame perfect equilibrium by fully delegating the intervention policy to the local agent. We turn to this in the next section. 
As a final point, our results are predicated on the existence of a conflict of interest between the local and the central supervisor, which here is represented by the difference between $A_{L}$ and $A_{C}$, and is at the root of why supervision may be centralized in the first place. This suggests that centralization may require measures to better align the incentives of local supervisors with those of the central authority beyond simply the imposition of tougher standards, or to better monitor the activities of local supervisors to ensure greater effort provision. One such measure can be found in the context of the SSM, where joint supervisory teams are intended to help attenuate agency problems that might otherwise exist. From a different perspective, one could well imagine that centralization could have the effect of reducing excess laxity by the local supervisor to the extent that a part of the intervention $\operatorname{cost} A_{L}$ represents regulatory capture by local interests, be it politicians, lobbyists, etc. In those cases, centralization may in fact reduce the perceived cost of intervention by the local supervisor (i.e., reduce $A_{L}$ ) if it changes the structure of reporting by local bank supervisors to their superiors, for instance. While ultimately one would still expect that $A_{L}>$ $A_{C}$, reducing this difference should be seen as part of the aim of an optimal centralization arrangement.

\subsubsection{Delegation of supervision}

So far we assumed that under centralization the central supervisor cannot commit to any strategy other than the subgame perfect one. However, the emergence of an equilibrium with lower inspection effort and worse bank portfolio quality than under independent supervision raises the question of whether the central supervisor would be better off by committing to another strategy. To see this, we study the case where the only credible alternative for the central supervisor is to delegate intervention policy to the local supervisor, that is, to allow her to operate as under full independence.

The central supervisor chooses between keeping control of supervision and delegating it 
to the local supervisor so as to maximize total surplus as given by

$$
\begin{aligned}
S W_{C} & =E\left[q\left(R-\frac{1}{2} c q-(1-k)\right)-(1-q)(1-k)-k\right] \\
& +e_{j} \operatorname{Pr}\left(q<\widetilde{q}_{j}\right) E\left[I_{C}\left(q_{j}^{*}, q, k\right) \mid q<\widetilde{q}_{j}\right]-\frac{d}{2} e_{j}^{2},
\end{aligned}
$$

where $j=L, C$. We have the following result.

Proposition 5 Suppose that $\psi_{C}=\psi_{L}$ and $A_{C}$ is such that a subgame optimal equilibrium under centralization with $e_{C}^{*}=0$ exists. In this equilibrium, the central supervisor is better off delegating supervision entirely to the local supervisor, and allowing her to choose the intervention threshold $\widetilde{q}_{L}$ and portfolio $q_{L}^{*}$ conditional on intervention.

The result implies that when the conflict between the central and the local supervisor is severe enough, the centralization of supervision is so ineffective that delegating all actions to the local supervisor is the best the central supervisor can do.

\subsubsection{Numerical examples}

Propositions 3 and 4 show that the centralization of supervision may lead to less information being collected in equilibrium if the conflict between the supervisors is sufficiently large. This results in a weaker intervention threat for banks since it is less likely that actionable information will be obtained. The consequence is that, despite the tougher regulatory standards, the equilibrium with centralized supervision may be worse than the equilibrium with local supervision both in terms of total surplus and in terms of banks' overall portfolio quality.

We show this with the help of a numerical example. We first derive an equilibrium under independent local supervision. Then, we analyze the case of centralization and show that there are values of $A_{C}$ such that there are equilibria with positive but lower supervisory effort and greater risk than under local supervision: $e_{C}^{*}<e_{L}^{*}, Q_{C}<Q_{L}$ and $Q_{C}^{*}<Q_{L}^{*}$.

For this example, we assume the following values: $R=2.5, c=3, d=0.04$ and $\eta=0.2$. Under local supervision we set the intervention cost and the social cost of bank failure equal to $A_{L}=0.25$ and $\psi_{L}=1.5$. Under centralized supervision we set $A_{C}=0.12637$ and $\psi_{C}=\psi_{L}=1.5$. This set of parameters ensures that the portfolio quality $q_{L}^{*}=q_{C}^{*}$ chosen by 
the supervisor upon intervention is an interior solution for all values of bank capital $k \in[0,1]$. It follows that also the intervention thresholds $\widetilde{q}_{L}$ and $\widetilde{q}_{C}$ under local and central supervision, respectively, as well as banks' laissez-faire portfolios $\widehat{q}$ are interior to $[0,1]$.

Figure 5 illustrates the equilibria in the different supervisory regimes. Under local supervision there is a unique equilibrium entailing a level of inspection effort $e_{L}^{*}=0.04085$. This intervention threat induces banks with capital $k$ between $\bar{k}_{L}^{*}=0.08782$ and $\widetilde{k}_{L}=0.18350$ to choose the intervention threshold $\widetilde{q}_{L}$, while banks with $k<\bar{k}_{L}^{*}$ and with $k>\widetilde{k}_{L}$ choose the laissez-faire quality $\widehat{q}$. The average portfolio quality chosen by banks ex ante is $Q_{L}=0.66895$; the one prevailing ex post, after the regulatory intervention, equals $Q_{L}^{*}=0.67159$.

Under centralized supervision there are three equilibria. Two of them feature positive inspection effort and one zero effort. In all equilibria, the inspection effort and the average bank portfolio quality are lower than under local supervision. The equilibrium under centralized supervision with the highest effort features $e_{C}^{*}=0.01514<e_{L}^{*}$ and $\bar{k}_{C}^{*}=0.35158>\bar{k}_{L}^{*}$. The corresponding ex ante average portfolio quality equals $Q_{C}=0.66782<Q_{L}$, while the ex post quality is $Q_{C}^{*}=0.66826<Q_{L}^{*}$. The other equilibrium with positive effort entails $e_{C}^{*^{\prime}}=0.01509$ and $\bar{k}_{C}^{*^{\prime}}=0.35166$ and average portfolio qualities $Q_{C}^{\prime}=667817$ and $Q_{C}^{*^{\prime}}=0.668254$. The third equilibrium features $e_{C}^{*^{\prime \prime}}=0$ and $\bar{k}_{C}^{*^{\prime \prime}}=\widetilde{k}_{L}$ since now no banks are disciplined. Given that supervision is ineffective with zero effort, banks' average portfolio qualities are as without supervision, that is $Q_{C}^{\prime \prime}=Q_{C}^{*^{\prime \prime}}=0 . \overline{6}$.

The example shows that when the conflict between the two supervisors, as represented by the difference $A_{L}-A_{C}$, is large enough, the solution under centralized supervision is worse than under independence in terms of inspection effort and risk of the banking system. This raises the question whether delegation to the local supervisor is better than centralized supervision.

To explore this, we compare the total surplus to the central supervisor under centralization and under delegation as given by (30) once the appropriate levels of supervisory effort $e_{j}$, intervention threshold $\widetilde{q}_{j}$, and portfolio quality upon successful intervention $q_{j}^{*}$ with $j=L, C$, are substituted in. Centralization entails an increase in surplus equal to $\Delta S W_{C}=0.000014$ and $\Delta S W_{C}^{\prime}=0.0000137$ in the two previously described equilibria with 


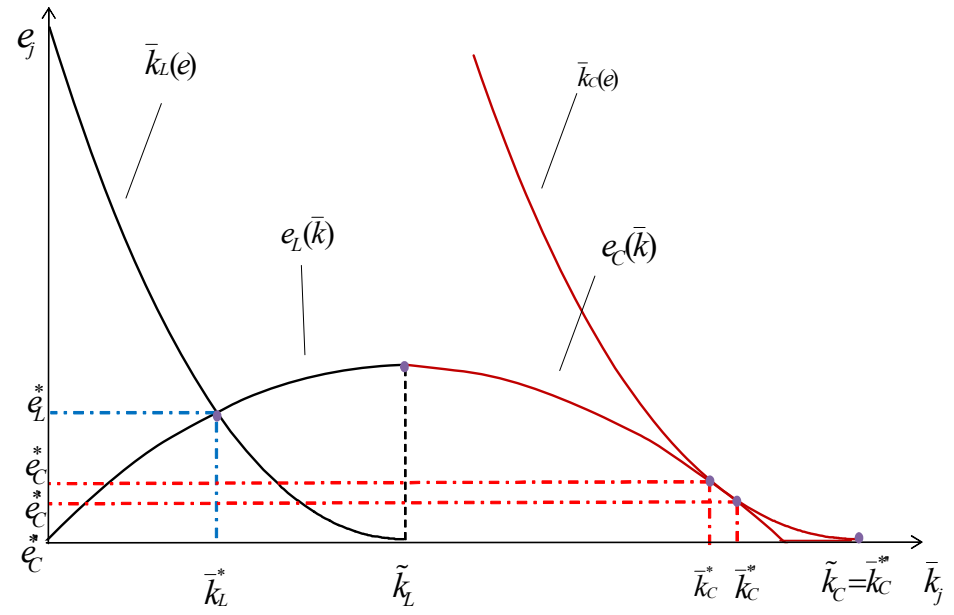

Figure 5: Equilibria under local and central supervision with $A_{C}=0.12637<A_{L}=0.25$.

positive effort, $\left(e_{C}^{*}, \bar{k}_{C}^{*}\right)$ and $\left(e_{C}^{*^{\prime}}, \bar{k}_{C}^{*^{\prime}}\right)$, respectively. By contrast, delegation increases surplus by $\Delta S W_{C}^{\prime \prime}=0.000122$ in the third equilibrium where centralization leads to zero supervisory effort. Thus, centralization is preferred as long as it leads to positive effort, while delegation is better in the extreme case where centralization leads to no effort.

\subsection{Higher cost of bank failure for the central supervisor: $A_{C}=A_{L}$ and $\psi_{C}>\psi_{L}$}

We now investigate the case where the central supervisor faces the same intervention cost as the local supervisor $A_{C}=A_{L}$, but bears a higher cost in case of bank failure, $\psi_{C}>\psi_{L}$. This implies again $\widetilde{q}_{C}>\widetilde{q}_{L}$, but also that $q_{C}^{*}>q_{L}^{*}$ so that the supervisor is now tougher in terms of both having a higher intervention threshold and adopting a higher standard conditional on intervention. It follows from Lemma 5 that the local supervisor's reaction function under centralization lies strictly below the one under local supervision (15) for $\bar{k}_{C} \leq \widetilde{k}_{L}$ because $I_{L}\left(q_{C}^{*}, \widehat{q}, k\right)<I_{C}\left(q_{L}^{*}, \widehat{q}, k\right)$ for any $\bar{k}_{C} \leq \widetilde{k}_{L}$. Also from Lemma 5 , the bank's reaction function $\bar{k}_{C}(e)$ under centralization remains strictly above the one under local supervision $\bar{k}_{L}(e)$.

Lemma 7 When $A_{C}=A_{L}$ and $\psi_{C}>\psi_{L}$, the local supervisor's reaction function under 
centralization is strictly below the reaction function under independence: $e_{C}(\bar{k})<e_{L}(\bar{k})$ for all $\bar{k}<\widetilde{k}_{C}$.

The lemma, which is a special case of Lemma 6, establishes that when the central supervisor is tougher because she internalizes a higher cost of bank failure, the local supervisor will react by, ceteris paribus, exerting less effort. The reason is simply that the difference in the failure costs translates into a difference in the portfolios that each supervisor would like to see implemented conditional on intervention, $q_{C}^{*}$ and $q_{L}^{*}$, so that even in cases where the local supervisor would like to intervene (because the bank has chosen an excessively risky portfolio), he does not get to implement his preferred portfolio. This conflict between the two supervisors reduces the incentives of the local supervisor to exert effort at identifying high-risk banks.

Figure 6 illustrates the result from Lemma 7. The red curve labeled $e_{C}$ represents the local supervisor's reaction function for effort when the central supervisor bears a higher cost of bank failure. In particular, $e_{C}$ is strictly below $e_{L}$ for all levels of the capital threshold $\bar{k}$, reflecting that, ceteris paribus, the local supervisor prefers to put in less effort than he would under independence. The curve labeled $\bar{k}_{C}$ represents the banks' reaction to the tougher standards, and is shifted out relative to the case of an independent local supervisor, much as in Section 5.2. Now, however, the implications of having a tougher central supervisor are more ambiguous: while banks respond by themselves adopting higher quality portfolios for a given level of effort, the supervisor responds by exerting less effort.

As in the previous case, the equilibrium under centralization depends on the size of the conflict between the local and the central supervisor. When such conflict is small, the equilibrium inspection effort may still be higher under centralization than under local supervision. When such conflict is large enough, the opposite holds. Moreover, we note that the condition for the existence of an equilibrium with zero supervisory effort under centralization as described in Proposition 4 still holds in the case of different costs of bank failure. This means there exists an equilibrium under centralization with $e_{C}^{*}=0$ in the case where $\psi_{C}>\psi_{L}$ if $A_{C} \leq \frac{1}{8 c}\left(\sqrt{3\left(8 c A_{L}-\psi_{L}^{2}\right)}-\psi_{L}\right)^{2}$. The reason is that, relative to the case with different intervention costs, in the case with $\psi_{C}>\psi_{L}$ the banks' reaction function is shifted further 


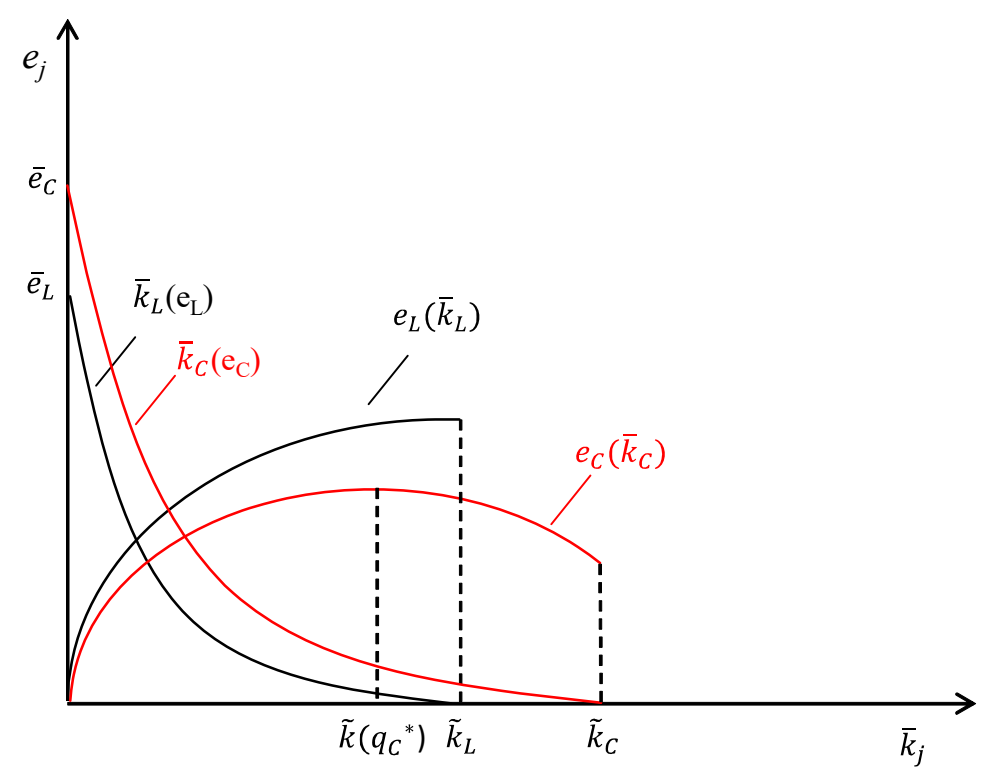

Figure 6: Equilibrium with central supervision when supervisors have different shadow costs of funds. The figure describes the bank's reaction function $\bar{k}_{j}\left(e_{j}\right)$ and the local supervisor's reaction function $e_{j}\left(\bar{k}_{j}\right)$ as a function of supervisory effort $e_{j}$ and bank capital threshold $\bar{k}_{j}$, respectively, with $j=L . C$.

out, while the supervisor's reaction function shifts further down. This implies that the condition $A_{C} \leq \frac{1}{8 c}\left(\sqrt{3\left(8 c A_{L}-\psi_{L}^{2}\right)}-\psi_{L}\right)^{2}$ is sufficient to have $e_{C}^{*}=0$ also in the case with $\psi_{C}>\psi_{L}$.

\subsubsection{Numerical example}

We now show with the help of a numerical example that centralizing supervision can lead to an equilibrium with lower (positive) supervisory effort and lower bank portfolio quality relative to the case with local supervision even in the case where the only source of conflict is the perceived cost of bank failure (i.e., $\psi_{C}>\psi_{L}$ ), but not the actual costs of intervention (i.e., $A_{C}=A_{L}$ ). As in Section 5.2.2, we first derive the equilibrium under local supervision and then show that there is a value of $\psi_{C}$ such that there is an equilibrium with $e_{C}^{*}<e_{L}^{*}$, $Q_{C}^{*}<Q_{L}^{*}$ and $Q_{C}<Q_{L}$

For this example, we slightly modify the parameters we used before. In particular, we maintain $R=2.5, c=3, d=0.04$ and $\eta=0.2$, but we now set $A_{L}=A_{C}=0.13, \psi_{L}=1.15$, and $\psi_{C}=1.45$. This set of parameters ensures again that all portfolio qualities, $q_{j}^{*}, \widetilde{q}_{j}$ and $\widehat{q}$ 


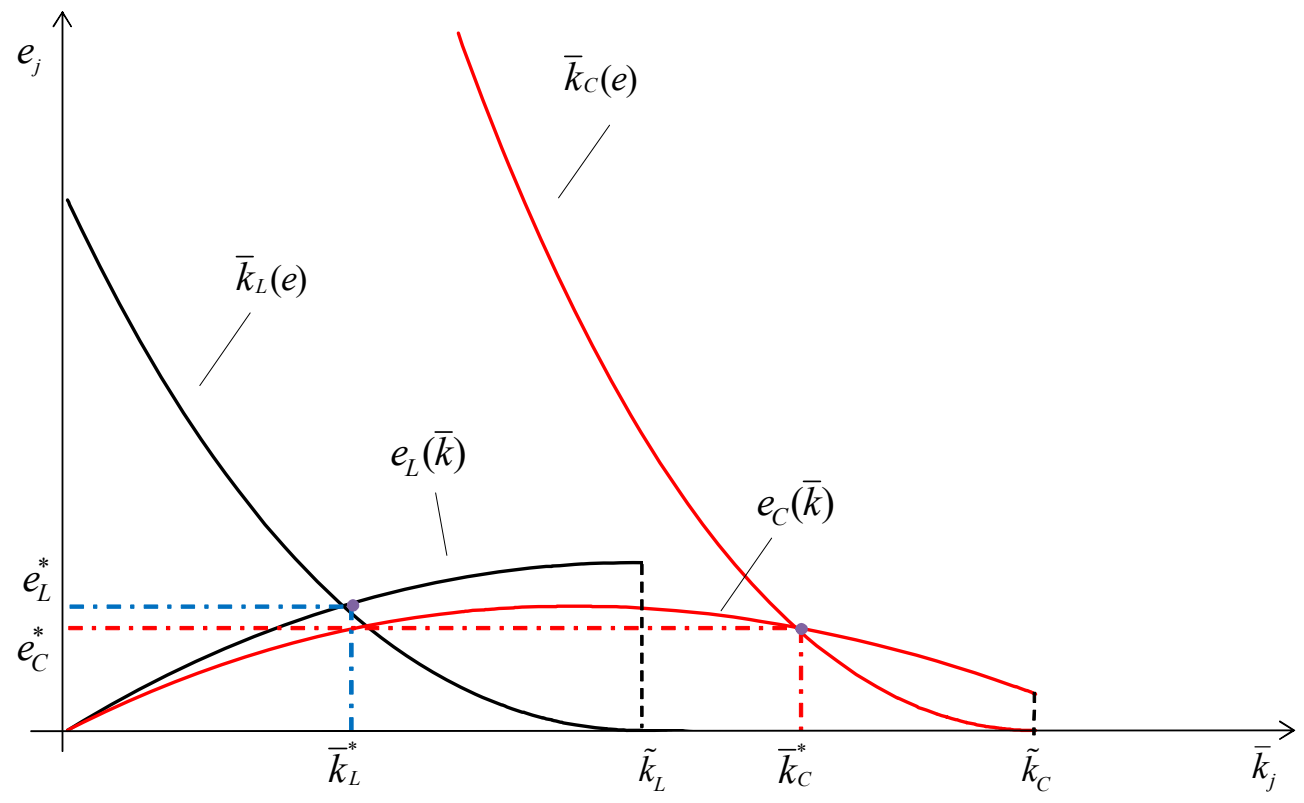

Figure 7: Equilibrium with local and central supervision with positive regulatory inspection effort for $\psi_{C}=1.45>\psi_{L}=1.15$.

are interior solutions for all $k \in[0,1]$, with $j=L, C$.

Figure 7 illustrates the equilibria under local and centralized supervision with this set of parameters. The equilibrium under local supervision entails a level of supervisory effort $e_{L}^{*}=0.03716$ and $k>\bar{k}_{L}^{*}=0.11124$. The average portfolio quality chosen by banks defined in $(26)$ is $Q_{L}=0.66946$, and the one prevailing after the regulatory intervention defined in (27) equals $Q_{L}^{*}=0.67256$. Under centralization, the equilibrium features $e_{C}^{*}=0.03081<e_{L}^{*}$, $\bar{k}_{C}^{*}=0.29380>\bar{k}_{L}^{*}, Q_{C}=0.66895<Q_{L}$ and $Q_{C}^{*}=0.66969<Q_{L}^{*}$. Despite the lower effort and the higher risk in the banking sector, the central supervisor still prefers the subgame optimal solution under centralization rather than to delegate the intervention policy to the supervisor, as the former brings an increase in surplus equal to $\Delta S W=0.0000994$. The result is thus similar to the case with different intervention costs: centralizing supervision can entail lower inspection effort and higher bank risk, but is nevertheless beneficial when inspection effort is still positive. The main difference is that the equilibrium with lower but positive inspection effort under centralization is now unique. 


\section{Conclusion}

This paper develops a simple model to analyze supervisory incentives and bank behavior. In the model, levered banks protected by limited liability invest in portfolios that are too risky from a social welfare perspective. Local supervisors are tasked with the day to day job of monitoring banks and identifying which have risky portfolios and are poorly capitalized, but the regulatory actions associated with identifying such banks are under the control of a central supervisor who may have different objectives.

We first show that the threat of regulatory intervention provides discipline against moral hazard by causing some banks to adjust their investment decisions and choose safer portfolios than they would otherwise. In equilibrium, however, there will be banks (the least capitalized ones) for which moral hazard is stronger than regulatory discipline. These will not comply with regulatory standards and will instead stick with their preferred portfolios, even at the risk of being intervened and losing the returns from their investments.

In our framework, under centralization, the local supervisor's incentives to collect information decrease relative to when she operates under full independence. The reason is that the information she collects might be used by the center to take actions that she dislikes. This agency conflict can lead to less information being collected and, as a result, worse quality portfolios on aggregate despite the higher regulatory standards.

Our analysis highlights the benefits and challenges of "hub-and-spokes" regulatory frameworks, such as the newly established Single Supervisory Mechanism (SSM) in the eurozone. We show that, to the extent that local agencies are perceived as softer than a central supervisor, centralization is likely to raise supervisory standards and deal with the perceived laxness and unwillingness to intervene that preceded the recent crisis. However, we also argue that, to the extent that the parties in charge of information collection and implementation continue to have different objectives, absent corrective mechanisms, the tougher standards may in fact lead to even greater risk taking and consequently an increased chance of systemic problems. Further, the agency problems at the source of this issue are larger the laxer the local supervisor. Hence, the problem may be the most severe exactly for those cases that could in principle benefit the most from centralized supervision. 
The design of the SSM implicitly takes into account these risks. First, the ECB retains the right to take any bank in the eurozone under direct supervision. In our model, this would act as a threat to the local supervisor and increase its payoff from exerting effort. Second, the new design puts all locally systemic banks under direct ECB supervision. This likely minimizes the difference between the local and central supervisors' utility functions. Indeed, banks that are locally systemic but not systemic for the eurozone as a whole are those for which views are most likely to differ. The fact that all euro level systemic banks also are under direct supervision has a similar effect, since these are the banks for which the externality from failure is likely to be valued differently by local and central supervisors. Third, internal governance practices such as having ECB employees heading on-site inspection teams and rotating staff of different nationality on these teams contributes to limit conflicts. 


\section{Appendix}

Proof of Proposition 1: Substituting the expression for $q_{L}^{*}(k)$ as in (4) into (5) and solving it equal to zero gives

$$
\widetilde{q}_{L}(k)=\frac{1}{c}\left(R+(1-k)\left(\psi_{L}-1\right) \pm \sqrt{2 c A_{L}}\right)
$$

We take the negative root for $\widetilde{q}_{L}$ as otherwise $\widetilde{q}_{L}(k)>q_{L}^{*}(k)$, which cannot be optimal given that it would imply an intervention threshold above the optimal portfolio quality chosen by the supervisor in case of intervention. It is immediate to see that for $\psi_{L}>1$, $\frac{\partial \widetilde{q}_{L}}{\partial k}=-\frac{1}{c}\left(\psi_{L}-1\right)<0, \frac{\partial \widetilde{q}_{L}}{\partial \psi_{L}}=\frac{1}{c}(1-k)>0$ and $\frac{\partial \widetilde{q}_{L}}{\partial A_{L}}=-\frac{1}{\sqrt{2 c A_{L}}}<0$.

Proof of Lemma 1: Substituting the expression for $\widetilde{q}_{L}(k)$ as in (6) into (10) and that for $\widehat{q}$ as in (1) into (9) and solving $\left.\Pi\left(\widetilde{q}_{L}\right)\right|_{k<\widetilde{k}_{L}}-\left.\Pi(\widehat{q})\right|_{k<\widetilde{k}_{L}}=0$ with respect to $k$ gives $\bar{k}_{L}(e)$ as in (11). Using the expression for $\widetilde{k}_{L}$ as in (8), it is easy to see that $\bar{k}_{L}(e)<\widetilde{k}_{L}$. Moreover, from (11) we have $\frac{\partial \bar{k}_{L}(e)}{\partial e}=-\frac{\psi_{L} R-\sqrt{2 c A_{L}}}{2 \sqrt{e \eta}\left(\psi_{L}+\sqrt{e \eta}\right)^{2}}<0, \frac{\partial \bar{k}_{L}(e)}{\partial \psi_{L}}=\frac{R \sqrt{e \eta}+\sqrt{2 c A_{L}}}{\left(\psi_{L}+\sqrt{e \eta}\right)^{2}}>0$ and $\frac{\partial \bar{k}_{L}(e)}{\partial A_{L}}=-\frac{c}{\sqrt{2 c A_{L}}\left(\psi_{L}+\sqrt{e \eta}\right)}<0$.

Proof of Lemma 2: Differentiating (14) with respect to $e$ and recalling that we have restricted $e$ to be less than $\bar{e}_{L}$ as in (12) gives

$$
e_{L}=\operatorname{Pr}\left(\widehat{q}<\widetilde{q}_{L}\right) E\left[I_{L}\left(q_{L}^{*}, \widehat{q}, k\right) \mid \widehat{q}<\widetilde{q}_{L}\right]<\bar{e}_{L}
$$

Further, from Lemma 1, it follows that in equilibrium $\operatorname{Pr}\left(\widehat{q}<\widetilde{q}_{L}\right)=\operatorname{Pr}\left(k<\bar{k}_{L}(e)\right)=$ $F\left(\bar{k}_{L}\right)$ and $E\left[I_{L}\left(q_{L}^{*}, \widehat{q}, k\right) \mid \widehat{q}<\widetilde{q}_{L}\right]=\frac{1}{F\left(\bar{k}_{L}\right)} \int_{0}^{\bar{k}_{L}} I_{L}\left(q_{L}^{*}, \widehat{q}, k\right) f(k) d k$. Substituting these into the expression above for $e_{L}$ gives (15). Differentiating this with respect to $\bar{k}_{L}$ gives $\frac{\partial e_{L}}{\partial \bar{k}_{L}}=$ $I_{L}\left(q_{L}^{*}, \widehat{q}\left(\bar{k}_{L}\right), \bar{k}_{L}\right) f\left(\bar{k}_{L}\right)>0$.

Proof of Proposition 2: To establish the existence and uniqueness of an equilibrium, recall first that we can focus on the equilibrium as a function of the supervisory effort $e_{L}$ and capital threshold level $\bar{k}_{L}$, rather than portfolio choice $q(k)$, since, as described in Lemma 1 , $\bar{k}_{L}$ provides a summary statistic of how supervisory effort affects bank risk taking behavior. Furthermore, from the lemmas above we have $\frac{\partial \bar{k}_{L}}{\partial e_{L}}<0$ and $\frac{\partial e_{L}}{\partial \bar{k}_{L}}>0$, so that the two reaction functions will intersect at most once. 
For $e=0$, the function $\bar{k}_{L}(e)$ equals the regulatory threshold $\widetilde{k}_{L}$, since for $e=0$ only banks with $k \geq \widetilde{k}_{L}$ will choose $q>\widetilde{q}_{L}$. Conversely, $\bar{k}_{L}(e)$ will equal 0 at $\bar{e}_{L}$ as defined in (12). It follows that, since the two functions can only cross once, we have $\bar{k}_{L}^{*} \in\left(0, \widetilde{k}_{L}\right)$ and $e_{L}^{*} \in\left(0, \bar{e}_{L}\right)$. To show that the solution must be strictly interior, note that $e_{L}^{* *}=\bar{e}_{L}$ cannot be an equilibrium as then $\bar{k}_{L}\left(\bar{e}_{L}\right)=0$ and all banks would choose $q \geq \widetilde{q}_{L}$. Given this, it cannot be optimal for the supervisor to choose $e_{L}^{, *}=\bar{e}_{L}$ since all banks are meeting the regulatory standards. Likewise, $\bar{k}_{L}^{*}=0$ cannot be an equilibrium as then the supervisor's optimal response would be to choose $e=0$, which would make the proposed solution of $\bar{k}_{L}^{*}=0$ not optimal for the banks. Therefore, the equilibrium must be strictly interior.

Proof of Lemma 4: The proof follows the same steps as the proof of Lemma 1. A bank with $k<\widetilde{k}_{C}$ will choose to switch from a portfolio of quality $\widehat{q}$ to one of quality $\widetilde{q}_{C}(k)$ if it has higher expected profit from doing so. The relevant expressions to compare are (10) using $\widetilde{q}_{C}(k)$ in place of $\widetilde{q}_{C}(k)$ and (9). Substituting the expression for $\widetilde{q}_{L}(k)$ as in (19) into (10) and $\widehat{q}$ as in (1) into (9), setting the difference equal to zero, and solving for $k$ gives $\bar{k}_{C}(e)$ as in (21). Comparing this to $\widetilde{k}_{C}$ as in $(20)$ gives $\bar{k}_{C}(e)<\widetilde{k}_{C}$. Moreover, it follows easily $\frac{\partial \bar{k}_{C}(e)}{\partial e}=-\frac{\psi_{C} R-\sqrt{2 c A_{C}}}{2 \sqrt{e \eta}\left(\psi_{C}+\sqrt{e \eta}\right)^{2}}<0, \frac{\partial \bar{k}_{C}(e)}{\partial \psi_{C}}=\frac{R \sqrt{e \eta}+\sqrt{2 c A_{C}}}{\left(\psi_{C}+\sqrt{e \eta}\right)^{2}}>0$ and $\frac{\partial \bar{k}_{C}(e)}{\partial A_{C}}=-\frac{c}{\sqrt{2 c A_{C}}\left(\psi_{C}+\sqrt{e \eta}\right)}<0$. The lemma follows.

Proof of Lemma 6: Differentiating (23) with respect to $e$ and recalling we have restricted $e$ to be less than $\bar{e}_{L}^{C}$ as given in (22) gives

$$
\begin{aligned}
e_{C}\left(\bar{k}_{C}\right) & =\operatorname{Pr}\left(\widehat{q}<\widetilde{q}\left(q_{C}^{*}\right)\right) E\left[I_{L}\left(q_{C}^{*}, \widehat{q}, k\right) \mid \widehat{q}<\widetilde{q}\left(q_{C}^{*}\right)\right] \\
& +\operatorname{Pr}\left(\widetilde{q}\left(q_{C}^{*}\right) \leq \widehat{q}<\widetilde{q}_{C}\right) E\left[I_{L}\left(q_{C}^{*}, \widehat{q}, k\right) \mid \widetilde{q}\left(q_{C}^{*}\right) \leq \widehat{q}<\widetilde{q}_{C}\right]<\bar{e}_{L}^{C} .
\end{aligned}
$$

This differs from (15) in two respects. First, if $q_{C}^{*}>q_{L}^{*}$, as is the case if $\psi_{C}>\psi_{L}$, then $E\left[I_{L}\left(q_{C}^{*}, \widehat{q}, k\right) \mid \widehat{q}<\widetilde{q}\left(q_{C}^{*}\right)\right]<E\left[I_{L}\left(q_{L}^{*}, \widehat{q}, k\right) \mid \widehat{q}<\widetilde{q}\left(q_{C}^{*}\right)\right]$. Second, $E\left[I_{L}\left(q_{C}^{*}, \widehat{q}, k\right) \mid \widetilde{q}\left(q_{C}^{*}\right) \leq \widehat{q}<\right.$ $\left.\widetilde{q}_{C}\right]<0$, meaning that relative to $(31)$ there is now an extra negative term in the supervisor's equation for effort choice. This implies that the reaction function $e_{C}\left(\bar{k}_{C}\right)$ lies weakly below $e_{L}\left(\bar{k}_{L}\right)$.

To characterize $e_{C}\left(\bar{k}_{C}\right)$, recall first that under laissez-faire banks choose $\widehat{q}<\widetilde{q}_{L}$ if $k<\widetilde{k}_{L}$ and that under centralization they choose $\widehat{q}<\widetilde{q}_{C}$ if $k<\bar{k}_{C}$, with $\widetilde{q}_{C}>\widetilde{q}_{L}$. We can then 
distinguish the case where $\bar{k}_{C}<\widetilde{k}_{L}$ and the case where $\bar{k}_{C}>\widetilde{k}_{L}$. The same argument applies here replacing $\widetilde{k}_{L}$ and $\widetilde{q}_{L}$ with $\widetilde{k}\left(q_{C}^{*}\right)$ and $\widetilde{q}\left(q_{C}^{*}\right)$, respectively. In the first case,

$$
\begin{aligned}
\operatorname{Pr}\left(\widehat{q}<\widetilde{q}_{L}\right) E\left[I_{L}\left(q_{C}^{*}, \widehat{q}, k\right) \mid \widehat{q}<\widetilde{q}_{L}\right] & =\frac{F\left(\bar{k}_{C}\right)}{F\left(\bar{k}_{C}\right)} \int_{0}^{\bar{k}_{C}} I_{L}\left(q_{C}^{*}, \widehat{q}, k\right) f(k) d k \\
& =\int_{0}^{\bar{k}_{C}} I_{L}\left(q_{C}^{*}, \widehat{q}, k\right) f(k) d k
\end{aligned}
$$

and $\operatorname{Pr}\left(\widetilde{q}_{L} \leq q<\widetilde{q}_{C}\right) E\left[I_{L}\left(q_{C}^{*}, \widehat{q}, k\right) \mid \widetilde{q}_{L} \leq \widehat{q}<\widetilde{q}_{C}\right]=0$. In the second case, when $\bar{k}_{C}>\widetilde{k}_{L}$,

$$
\begin{aligned}
\operatorname{Pr}\left(\widehat{q}<\widetilde{q}\left(q_{C}^{*}\right)\right) E\left[I_{L}\left(q_{C}^{*}, \widehat{q}, k\right) \mid \widehat{q}<\widetilde{q}\left(q_{C}^{*}\right)\right] & =\frac{F\left(\widetilde{k}\left(q_{C}^{*}\right)\right)}{F\left(\widetilde{k}\left(q_{C}^{*}\right)\right)} \int_{0}^{\widetilde{k}\left(q_{C}^{*}\right)} I_{L}\left(q_{C}^{*}, \widehat{q}, k\right) f(k) d k \\
& =\int_{0}^{\widetilde{k}\left(q_{C}^{*}\right)} I_{L}\left(q_{C}^{*}, \widehat{q}, k\right) f(k) d k
\end{aligned}
$$

and

$$
\begin{aligned}
\operatorname{Pr}\left(\widetilde{q}\left(q_{C}^{*}\right) \leq q<\widetilde{q}_{C}\right) E\left[I_{L}\left(q_{C}^{*}, \widehat{q}, k\right) \mid \widetilde{q}\left(q_{C}^{*}\right) \leq q<\widetilde{q}_{C}\right] & =\frac{\left[F\left(\bar{k}_{C}\right)-F\left(\widetilde{k}\left(q_{C}^{*}\right)\right)\right]}{F\left(\bar{k}_{C}\right)-F\left(\widetilde{k}\left(q_{C}^{*}\right)\right)} \int_{\widetilde{k}\left(q_{C}^{*}\right)}^{\bar{k}_{C}} I_{L}\left(q_{C}^{*}, \widehat{q}, k\right) f(k) d k \\
& =\int_{\widetilde{k}\left(q_{C}^{*}\right)}^{\bar{k}_{C}} I_{L}\left(q_{C}^{*}, \widehat{q}, k\right) f(k) d k
\end{aligned}
$$

The lemma follows.

Proof of Proposition 3: Since $\psi_{C}=\psi_{L}$, at $A_{L}=A_{C}$ we have $e_{C}^{*}=e_{L}^{*}$. Also, since at $e_{L}^{*}$ the regulator's reaction function is upward sloping and $\frac{\partial \bar{k}_{C}}{\partial A_{C}}<0$, we have that $\frac{\partial e_{C}^{*}}{\partial A_{C}}<0$. By continuity, there exists a $\delta>0$ such that for all $A_{C} \in\left(A_{L}-\delta, A_{L}\right), e_{C}^{*}>e_{L}^{*}$.

Now turn to banks' portfolio quality. From the discussion following Lemma 5 we know that for constant effort $\widetilde{k}_{C}-\bar{k}_{C}(e)>\widetilde{k}_{L}-\bar{k}_{L}(e)$, which in turn implies that $Q_{C}>Q_{L}$ and $Q_{C}^{*}>Q_{L}^{*}$ since $e_{C}^{*}>e_{L}^{*}$, which increases the weight of the second term in $Q_{j}^{*}$ as given (27), for $j=C, L$.

Proof of Proposition 4: Setting (28) equal to zero and solving for $\bar{k}$, and taking the smallest root which gives a positive value for $\bar{k}$ gives

$$
\bar{k}_{0}=\frac{1}{\left(2 \psi_{L}-\psi_{C}\right) \psi_{C}}\left(\left(3 \psi_{L}-\psi_{C}\right) \psi_{C}-\frac{1}{2} \psi_{C}^{2}-\frac{1}{2} \sqrt{3} \sqrt{\left(2 \psi_{L}-\psi_{C}\right) \psi_{C}\left(8 c A_{L}-\psi_{C}\left(2 \psi_{L}-\psi_{C}\right)\right)}\right)
$$


When $\psi_{C}=\psi_{L}$ this simplifies to

$$
\bar{k}_{0}=\frac{3}{2}-\frac{1}{2 \psi_{L}} \sqrt{3\left(8 c A_{L}-\psi_{L}^{2}\right)} .
$$

We then compare $\bar{k}_{0}$ and $\widetilde{k}_{C}$ as given by (20). We have that $\bar{k}_{0} \leq \widetilde{k}_{C}$ if

$$
\frac{1}{2}-\frac{1}{2 \psi_{L}} \sqrt{3\left(8 c A_{L}-\psi_{L}^{2}\right)} \leq-\frac{1}{\psi_{L}} \sqrt{2 c A_{C}}
$$

or, equivalently, if

$$
A_{C} \leq \frac{1}{8 c}\left(\sqrt{3\left(8 c A_{L}-\psi_{L}^{2}\right)}-\psi_{L}\right)^{2} .
$$

When (32) is satisfied, the local regulator's reaction function under centralization is positive for $\bar{k}<\bar{k}_{0}<\widetilde{k}_{C}$ and zero for $\bar{k}_{0} \leq \bar{k} \leq \widetilde{k}_{C}$. This, together with the fact that the bank's reaction function $\bar{k}_{C}(e)$ crosses the $e=0$ axis at $\widetilde{k}_{C}$, implies that an equilibrium with $\left(e_{C}^{*}, \bar{k}_{C}\right)=\left(0, \widetilde{k}_{C}\right)$ exists.

When $e_{C}^{*}=0$, the central supervisor never intervenes and thus banks always choose their preferred portfolio quality $\widehat{q}$. From the comparison of the expressions for $Q_{I}$ and $Q_{I}^{*}$ for $e_{L}^{*}>0$ and $e_{C}^{*}=0$ given in (26) and (27), it follows $Q_{C}^{*}<Q_{L}^{*}$ and $Q_{C}<Q_{L}$ for $e_{C}^{*}=0$.

Proof of Proposition 5: When $e_{C}=0$, the last two terms in (30) are zero so that under centralized supervision

$$
S W_{C}=E\left[q\left(R-\frac{1}{2} c q-(1-k)\right)-(1-q)(1-k)-k\right] .
$$

By contrast, under delegation

$$
S W_{C}=E\left[q\left(R-\frac{1}{2} c q-(1-k)\right)-(1-q)(1-k)-k\right]+e_{L} \operatorname{Pr}\left(q<\widetilde{q}_{L}\right) E\left[I_{C}\left(q_{L}^{*}, q, k\right) \mid q<\widetilde{q}_{L}\right]-\frac{d}{2} e_{L}^{2} .
$$

Moreover, we have

$e_{L} \operatorname{Pr}\left(q<\widetilde{q}_{L}\right) E\left[I_{C}\left(q_{L}^{*}, q, k\right) \mid q<\widetilde{q}_{L}\right]-\frac{d}{2} e_{L}^{2}>e_{L} \operatorname{Pr}\left(q<\widetilde{q}_{L}\right) E\left[I_{L}\left(q_{L}^{*}, q, k\right) \mid q<\widetilde{q}_{L}\right]-\frac{d}{2} e_{L}^{2}>0$

since $A_{C}<A_{L}$. The proposition follows.

Proof of Lemma 7: Recall that the reaction function under centralization is given by

$$
e_{C}\left(\bar{k}_{C}\right)=\int_{0}^{\min \left(\bar{k}_{C}, \widetilde{k}\left(q_{C}^{*}\right)\right)} I_{L}\left(q_{C}^{*}, \widehat{q}, k\right) f(k) d k+\mathbf{1}_{\bar{k}_{C}>\widetilde{k}\left(q_{C}^{*}\right)} \int_{\widetilde{k}\left(q_{C}^{*}\right)}^{\bar{k}_{C}} I_{L}\left(q_{C}^{*}, \widehat{q}, k\right) f(k) d k<\bar{e}_{C},
$$


where $\widetilde{k}\left(q_{C}^{*}\right) \leq \widetilde{k}_{L}$. Given that $E\left[I_{L}\left(q_{C}^{*}, \widehat{q}, k\right) \mid \widehat{q}<\widetilde{q}\left(q_{C}^{*}\right)\right]<E\left[I_{L}\left(q_{L}^{*}, \widehat{q}, k\right) \mid \widehat{q}<\widetilde{q}\left(q_{C}^{*}\right)\right]$ if $q_{C}^{*} \neq q_{L}^{*}$, this establishes that $e_{C}(\bar{k})<e_{L}(\bar{k})$ for $\bar{k}<\widetilde{k}\left(q_{C}^{*}\right)<\widetilde{k}_{L}$. For $\bar{k}>\widetilde{k}\left(q_{C}^{*}\right)$, we have that $E\left[I_{L}\left(q_{C}^{*}, \widehat{q}, k\right) \mid \widetilde{q}\left(q_{C}^{*}\right) \leq \widehat{q}<\widetilde{q}_{C}\right]<0$, so the result trivially follows also for $\bar{k}>\widetilde{k}\left(q_{C}^{*}\right)$. 


\section{References}

[1] Acharya, Viral, 2003, "Is the International Convergence of Capital Adequacy Regulation Desirable?", Journal of Finance, 58(6), pp. 2745-2781.

[2] Acharya, Viral, Itamar Drechsler, and Philipp Schnabl , 2013, "A Pyrrhic Victory? Bank Bailouts and Sovereign Credit Risk," Journal of Finance, forthcoming.

[3] Agarwal, Sumit, David Lucca, Amit Seru, and Francesco Trebbi, 2014, "Inconsistent Regulators: Evidence from Banking," Quarterly Journal of Economics, 129(2), pp.889938.

[4] Aghion, Philippe, and Jean Tirole, 1997, "Formal and Real Authority in Organizations," Journal of Political Economy, 105(1), pp. 1-29.

[5] Basel Committee on Banking Supervision, 2010, "Report and Recommendations of the Cross-border Bank Resolution Group", BIS, Basel.

[6] Beck, Thorsten, and Wolf Wagner, 2014, "Supranational Supervision - How Much and for Whom?", International Journal of Central Banking, forthcoming.

[7] Beck, Thorsten, Radomir Todorov, and Wolf Wagner, 2013, "Supervising Cross-border Banks: Theory, Evidence and Policy," Economic Policy January 2013, pp. 5-44.

[8] Bolton, Patrick, and Martin Oehmke, 2015, "Bank Resolution and the Structure of Global Banks," working paper, Columbia University.

[9] Calzolari, Giacomo, and Gyongyi Loranth, 2011, "Regulation of Multinational Banks: A Theoretical Inquiry," Journal of Financial Intermediation, 20(2), pp. 178-198

[10] Calzolari, Giacomo, Jean-Edouard Colliard, and Gyongyi Loranth, 2015, "Multinational Banks and Supranational Supervision," working paper.

[11] Colliard, Jean-Edouard, 2015, "Optimal Supervisory Architecture and Financial Integration in a Banking Union," Working paper 1786, European Central Bank. 
[12] Dell'Ariccia, Giovanni, and Robert Marquez, 2006, "Competition among Regulators and Credit Market Integration", Journal of Financial Economics, 79, pp. 401-430.

[13] Farhi, Emmanuel, and Jean Tirole, 2014, "Deadly Embrace: Sovereign and Financial Balance Sheets Doom Loops", mimeo, Harvard University.

[14] Goyal, Rishi, Petya Koeva Brooks, Mahmood Pradhan, Thierry Tressel, Giovanni Dell'Ariccia, and Ceyla Pazarbasioglu, 2013, "A Banking Union for the Euro Area" IMF Staff Discussion Notes No. 13/1.

[15] Hellmann, T., Murdock, K., Stiglitz, J., 2000, "Liberalization, Moral Hazard in Banking, and Prudential Regulation: Are Capital Requirements Enough?" American Economic Review, 90, 147-165.

[16] Holthausen, Cornelia, and Thomas Rønde, 2004, "Cooperation in International Banking Supervision" ECB Working Paper No. 316.

[17] IMF, 2010, "Resolution of Cross-Border Banks-A Proposed Framework for Enhanced Coordination".

[18] Mailath, George, and Loretta Mester, 1994, "A Positive Analysis of Bank Closure," Journal of Financial Intermediation, 3, pp. 272-299.

[19] Matutes, Carmen, and Xavier Vives, 2000, "Imperfect Competition, Risk Taking, and Regulation in Banking," European Economic Review, 44, 1-34.

[20] Morrison, Alan, and Lucy White, 2009, "Level Playing Field in International Financial Regulation", Journal of Finance, 64(3), pp. 1099-1142.

[21] Morrison, Alan, and Lucy White, 2013, "Reputational Contagion and Optimal Regulatory Forbearance", Journal of Financial Economics, 110(3), pp. 642-658.

[22] Obstfeld, Maurice, 2014, "Trilemmas and Tradeoffs: Living with Financial Globalization", mimeo UC Berkeley. 
[23] Repullo, R., 2004, "Capital requirements, Market Power, and Risk-taking in Banking," Journal of Financial Intermediation, 13, 156-182.

[24] Schoenmaker, Dirk, 2011, "The Financial Trilemma", Economic Letters, 111, pp. 57-59.

[25] Walther, Ansgar, and Lucy White, 2015, "Rules versus discretion in bank resolution", working paper, HBS and Oxford University. 